ARTICLE

\title{
Sphingosine-1-phosphate receptor 3 promotes leukocyte rolling by mobilizing endothelial P-selectin
}

Claudia Nussbaum ${ }^{1,2, \star}$, Sarah Bannenberg ${ }^{3, \star}$, Petra Keul ${ }^{3}$, Markus H. Gräler ${ }^{4}$, Cassiano F. Gonçalves-deAlbuquerque ${ }^{1,5}$, Hanna Korhonen ${ }^{6}$, Karin von Wnuck Lipinski ${ }^{3}$, Gerd Heusch ${ }^{3}$, Hugo C. de Castro Faria Neto ${ }^{5}$, Ina Rohwedder ${ }^{1}$, Joachim R. Göthert ${ }^{7}$, Vysakh Pushpa Prasad ${ }^{8}$, Günter Haufe ${ }^{8}$, Baerbel Lange-Sperandio ${ }^{2}$, Stefan Offermanns ${ }^{6}$, Markus Sperandio ${ }^{1, \star} \&$ Bodo Levkau ${ }^{3, \star}$

Sphingosine-1-phosphate (S1P) participates in inflammation; however, its role in leukocyte rolling is still unclear. Here we use intravital microscopy in inflamed mouse cremaster muscle venules and human endothelial cells to show that S1P contributes to P-selectin-dependent leukocyte rolling through endothelial S1P receptor $3\left(\mathrm{~S} 1 \mathrm{P}_{3}\right)$ and $\mathrm{G} \alpha_{\mathrm{q}}, \mathrm{PLC} \beta$ and $\mathrm{Ca}{ }^{2}+$. Intraarterial S1P administration increases leukocyte rolling, while $\mathrm{S}_{3} \mathrm{P}_{3}$ deficiency or inhibition dramatically reduces it. Mast cells involved in triggering rolling also release S1P that mobilizes $\mathrm{P}$-selectin through $\mathrm{S}_{\mathrm{P}}$. Histamine and epinephrine require $\mathrm{S}_{3} \mathrm{P}_{3}$ for full-scale effect accomplishing it by stimulating sphingosine kinase 1 (Sphk1). In a counter-regulatory manner,

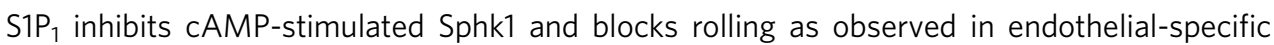
$S 1 P_{1}^{-/-}$mice. In agreement with a dominant pro-rolling effect of $\mathrm{STP}_{3}$, FTY720 inhibits rolling in control and $S 1 P_{1}^{-} /-$but not in $S 1 P_{3}^{-/-}$mice. Our findings identify S1P as a direct and indirect contributor to leukocyte rolling and characterize the receptors mediating its action.

\footnotetext{
${ }^{1}$ Walter Brendel Center, Ludwig Maximilians Universität München, 81377 München, Germany. ${ }^{2}$ Dr v. Haunersches Children's Hospital, Ludwig Maximilians University München, 80337 München, Germany. ${ }^{3}$ Institute of Pathophysiology, West German Heart and Vascular Center, University Hospital Essen, University of Duisburg-Essen, 45122 Essen, Germany. ${ }^{4}$ Department of Anesthesiology and Intensive Care Medicine, Center for Sepsis Control and Care, Center for Molecular Biomedicine, University Hospital Jena, 07745 Jena, Germany. ${ }^{5}$ Laboratorio de Imunofarmacologia, Instituto Oswaldo Cruz, Fiocruz, Rio de Janeiro 21040900, Brazil. ${ }^{6}$ Max Planck Institute for Heart and Lung Research, 61231 Bad Nauheim, Germany. ${ }^{7}$ Department of Hematology, University Hospital Essen, University of Duisburg-Essen, 45122 Essen, Germany. ${ }^{8}$ Organisch-Chemisches Institut, Westfälische Wilhelms-Universität Münster, 48149 Münster, Germany. * These authors contributed equally to this work. Correspondence and requests for materials should be addressed to M.S. (email: markus.sperandio@lmu.de) or to B.L. (email: bodo.levkau@uni-due.de).
} 
S phingosine-1-phospate (S1P) is a bioactive lysophospholipid with important functions in the immune and cardiovascular systems and has been implicated in different aspects of inflammatory disorders ${ }^{1}$. High S1P concentrations have been measured locally at inflammatory sites ${ }^{2,3}$, where it is generated by sphingosine kinases activated through inflammatory cytokines, lipopolysaccharide (LPS) or thrombin. This suggests a role for S1P in the propagation of the inflammatory response ${ }^{4}$. In contrast, S1P opposes the pathologically increased endothelial permeability common to all inflammatory processes and prevents vascular leakage caused by LPS, thrombin or platelet-activating factor $^{5-7}$. There is also evidence both for stimulatory and inhibitory effects of S1P on leukocyte recruitment in inflammation. In favour of a pro-inflammatory role, exogenous S1P induces endothelial vascular cell adhesion molecule 1 (VCAM-1) and E-selectin, while endogenous S1P mediates the stimulatory effect of tumor-necrosis factor (TNF)- $\alpha$ and LPS on adhesion molecules, which is suppressed by $\mathrm{S}_{1} \mathrm{P}_{1}$ short interfering $\mathrm{RNA}^{8-10}$. In support, chronic overexpression of sphingosine kinase 1 augments VCAM-1 and E-selectin expression and enhances neutrophil adhesion after TNF- $\alpha^{11}$. In contrast, both $\mathrm{S} 1 \mathrm{P}$ and $\mathrm{S}_{1} \mathrm{P}_{1}$ agonists have been demonstrated to inhibit TNF- $\alpha$ induced endothelial adhesion molecule expression and adherence of inflammatory cells by interfering with endothelial NF- $\kappa \mathrm{B}$ and stimulating nitric oxide production ${ }^{12-14}$. Several explanations have been put forward for these apparent discrepancies such as the assumption that S1P receptors may be differentially expressed among endothelial beds, and that the wide range of S1P concentrations employed in the individual studies may have led to contrary effects as observed for S1P in other systems ${ }^{15}$. However, in all these studies the focus has been on $\mathrm{S}_{1} \mathrm{P}_{1}$, while any involvement of $\mathrm{S} 1 \mathrm{P}$ receptor $3\left(\mathrm{~S}_{1} \mathrm{P}_{3}\right)$ has not been addressed.

In contrast to the effects of S1P on firm leukocyte adhesion, its role on leukocyte rolling - the crucial initial step of inflammatory cell recruitment-has not been investigated in detail. Recently, sphingosine kinase-1 has been shown to contribute to histamineinduced leukocyte rolling, but the mechanism of action has remained elusive ${ }^{16}$. In general, leukocyte capture and rolling is mediated by the selectin family of adhesion molecules consisting of three selectins: L-, E- and P-selectin ${ }^{17,18}$. L-selectin is expressed on most leukocytes and mediates leukocyte capture and rolling through binding to selectin ligands found on high endothelial venules of lymphoid organs. E-selectin and P-selectin are expressed on the activated vascular endothelium during inflammation and mediate rolling through binding to carbohydrate moieties of selectin ligands on leukocytes ${ }^{17,18}$. Among the selectins, P-selectin contributes to disease pathology in many experimental models including myocardial and renal infarction, thrombosis, stroke, atherosclerosis, cerebral malaria and sickle cell disease ${ }^{19}$, as has been shown using P-selectin-blocking antibodies and knockout strategies in mouse, feline and baboon models ${ }^{20-23}$.

We have recently identified leukocyte recruitment defects in $\mathrm{S}_{\mathrm{P}} \mathrm{P}_{3}^{-/-}$mice in atherosclerosis and peritoneal inflammation that were caused by both haematopoietic and non-haematopoietic $\mathrm{S} \mathrm{P}_{3}$ deficiency ${ }^{3}$. In addition, treatment with the S1P analogue FTY720 severely reduced leukocyte recruitment into the inflamed peritoneum ${ }^{3}$. Currently, it is controversial if S1P in general and $\mathrm{S}_{1} \mathrm{P}_{3}$ in particular affect leukocyte rolling.

In this study, we address this issue by studying P-selectindependent leukocyte rolling in surgically prepared post-capillary venules of the mouse cremaster muscle in vivo. These studies are complemented by experiments in a novel in vitro system to investigate the mechanisms of the rapid P-selectin mobilization that occurs within minutes in endothelial cells and stems from the exocytosis of Weibel-Palade bodies. Our results demonstrate a unique role of $\mathrm{S} 1 \mathrm{P}$ and $\mathrm{S}_{1} \mathrm{P}_{3}$ in $\mathrm{P}$-selectin-dependent rolling both by direct action as well as by contributing to P-selectin mobilization by other agonists.

\section{Results}

$\mathrm{S} \mathrm{P}_{3}$ deficiency and inhibition reduce leukocyte rolling. To examine whether $\mathrm{S}_{3} \mathrm{P}_{3}$ plays a role in $\mathrm{P}$-selectin-dependent leukocyte rolling in vivo, we employed intravital microscopy to monitor rolling in post-capillary venules of the surgically exteriorized mouse cremaster muscle ${ }^{24,25}$. In this model, profound spontaneous leukocyte rolling is induced by the surgical preparation of the cremaster (hence termed trauma), which exclusively depends on the rapid mobilization of P-selectin from endothelial Weibel-Palade bodies to the luminal surface in its initial phase $(<45 \mathrm{~min}$ after exteriorization of the cremaster muscle $)^{17,26-28}$. Elegant studies from the 1990s have shown that the endothelial P-selectin mobilization is in large part caused by activation products of tissue mast cells released upon mechanical manipulation during surgery ${ }^{29}$. Here we employed this model to study leukocyte rolling in $S 1 P_{3}^{-/-}$mice and observed that their rolling flux fraction (as a measure of rolling) was greatly diminished compared with C57Bl6 controls (Fig. 1a). Neither microvascular/haemodynamic conditions nor leukocyte rolling velocities differed between groups excluding any bias by these variables (Table 1 and Supplementary Fig. 1). Systemic application of a P-selectin-blocking antibody completely abrogated leukocyte rolling in both genotypes (Fig. 1a) confirming the dependence of rolling on P-selectin in this model and both genotypes, respectively. In addition, wholemount immunohistochemistry for intravascular P-selectin clearly showed the appearance of luminal P-selectin in controls but not in $S 1 P_{3}^{-/-}$mice (Fig. 1a). Of note, $\mathrm{S}_{1} \mathrm{P}_{3}$-deficient leukocytes had no intrinsic defect in rolling as we determined in an ex vivo flow chamber system ${ }^{30}$, where blood was diverted from the carotid artery into microflow chambers coated with immobilized murine P-selectin ${ }^{31}$ (Fig. 1b). We also assessed cell surface expression of P-selectin glycoprotein ligand-1 as the main, if not only, functional P-selectin ligand on neutrophils, and found no differences between $\mathrm{S}_{1} \mathrm{P}_{3}^{-/-}$and $\mathrm{C} 57 \mathrm{Bl6}$ mice (Supplementary Table 1).

We next tested the effect of TY-52156, a highly specific $\mathrm{S}_{3} \mathrm{P}_{3}$ inhibitor $^{32}$, on leukocyte rolling in C57Bl6 mice. As TY-52156 is not commercially available, we synthesized it according to published protocols ${ }^{32}$ and confirmed its specificity for $\mathrm{S}_{1} \mathrm{P}_{3}$ in comparison to $\mathrm{S}_{1} \mathrm{P}_{1}$ (Supplementary Figs 2,3). Intraperitoneal administration of TY-52156 (1.25 mg per kg body weight) $30 \mathrm{~min}$ before the experiment leads to a dramatic reduction in leukocyte rolling (Fig. 1c). To test whether the opposite-stimulation of the vasculature by exogenous $\mathrm{S} 1 \mathrm{P}$-would increase rolling, we injected S1P directly into the carotid artery $(30 \mu \mathrm{g}$ per $\mathrm{kg}$ body weight $)$ in C57Bl6 mice and measured leukocyte rolling immediately thereafter. Indeed, we observed that rolling was dramatically enhanced by S1P (Fig. 1d).

$\mathrm{S} \mathrm{P}_{3}$ induces $\mathrm{P}$-selectin and rolling via $\mathrm{G}_{\mathrm{q}}, \mathrm{PLC}$ and $\mathrm{Ca}^{2+}$. Exposure of cell surface P-selectin on luminal endothelial cells is the prerequisite for trauma-induced leukocyte rolling in the experimental model we have used here ${ }^{17,26-28}$. To pursue the mechanism by which $\mathrm{S} 1 \mathrm{P}$ and $\mathrm{S}_{1} \mathrm{P}_{3}$ affect $\mathrm{P}$-selectin mobilization, we established an assay for quantitative assessment of cell surface P-selectin using flow cytometry in human umbilical endothelial cells (HUVECs) as the only system applicable for such studies. Nevertheless, HUVECs are still extremely difficult to work with in respect to studying P-selectin as they express it only under certain culture conditions and lose ability for mobilizing it already after one to two passages. Nevertheless, we successfully established the 

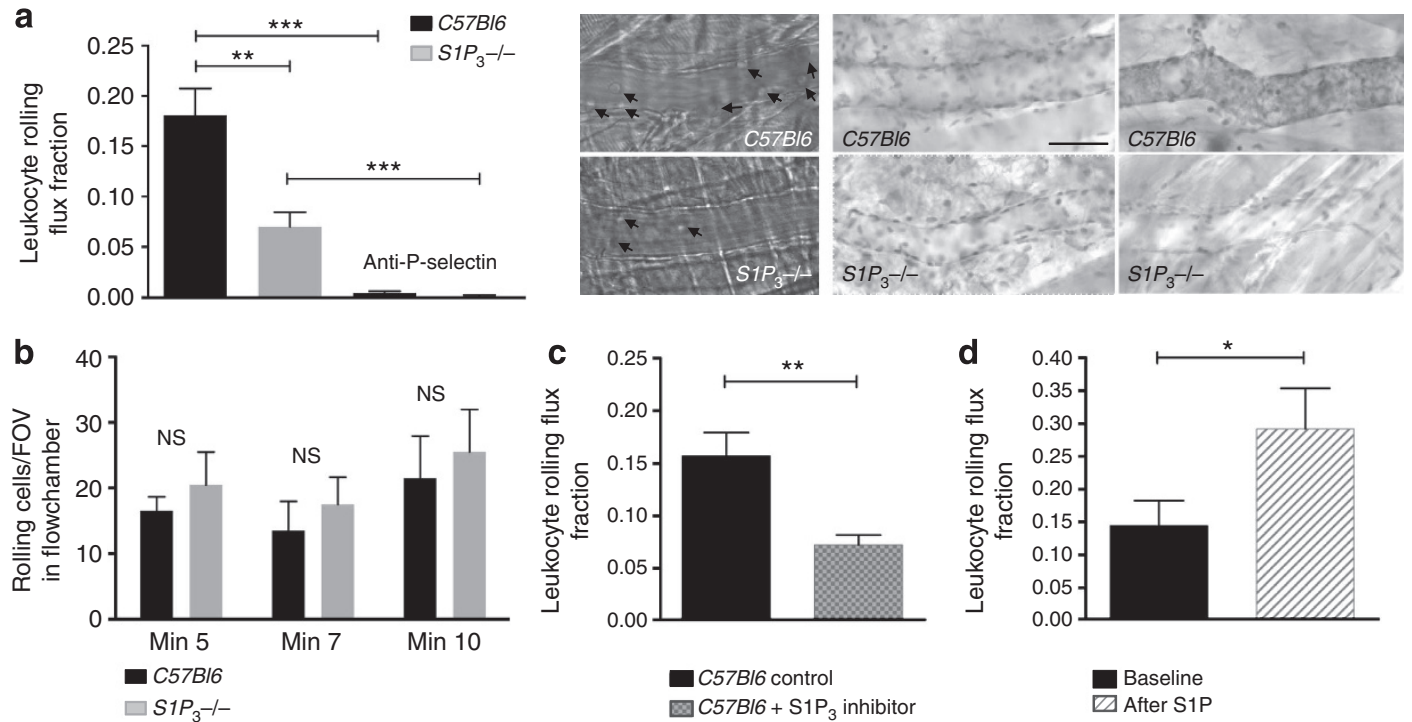

Figure 1 | Leukocyte rolling is reduced in $\mathbf{S 1 \mathbf { P } _ { \mathbf { 3 } } ^ { - }} \mathbf{-}^{-}$mice and after $\mathbf{S 1 P}_{\mathbf{3}}$ blockade, respectively, and is enhanced by S1P administration. Leukocyte rolling was quantified in postcapillary venules of the cremaster muscle of (a) S1P ${ }_{3}^{-/-}$mice $(n=5)$ and C57BI6 controls $(n=6)$. Rolling was abolished by systemic injection of a P-selectin-blocking antibody in both groups. Middle: representative snap shot images of rolling leukocytes (arrows) are shown. Right: representative whole-mount immunohistochemistry for P-Selectin after in vivo injection of an anti-P-selectin antibody (left: no staining in uninjured cremaster, right: luminal P-selectin staining in the contralateral exteriorized cremaster). Scale bar, $40 \mu \mathrm{m}$. (b) Unaltered rolling of $S 1 P_{3}^{-} /-$leukocytes on immobilized P-selectin. Microflow chambers were coated with recombinant murine P-selectin and perfused with arterial blood diverted from the carotid artery of C57B16 and S1P ${ }_{3}^{-/-}$mice ( $n=3$ each) for the indicated times. The number of rolling cells was quantified per field of view (FOV). (c) Rolling in C57Bl6 mice with $(n=4)$ and without $(n=5)$ the $\mathrm{S}_{3} \mathrm{P}_{3}$ inhibitor TY-52156 (1.25 mg kg ${ }^{-1}$ intraperitoneally (i.p.) 30 min before experiment). (d) Rolling in C57Bl6 mice at baseline and immediately after S1P injection into the carotid artery (30 $\left.\mu \mathrm{kg}^{-1}, n=5\right)$. Quantitative data are presented as mean \pm s.e.m. Significance was established using a Wilcoxon rank sum test or a paired two-tailed Student's $t$-test. In all experiments: ${ }^{\star} P<0.05 ;{ }^{\star \star} P<0.01 ;{ }^{\star \star \star \star} P<0.001$.

assay and validated it extensively using histamine and $\mathrm{H} 1$ and $\mathrm{H} 2$ receptor antagonists (Supplementary Fig. 4). Using this assay, we observed that stimulation of HUVEC with $1 \mu \mathrm{M}$ S1P resulted in an extremely rapid (within $5 \mathrm{~min}$ ) appearance of P-selectin on the cell surface (Fig. 2a). In contrast, the agonist of the $\mathrm{S}_{1} \mathrm{P}_{1}$ receptor SEW2871 was ineffective (Fig. 2a). In agreement with a role of $\mathrm{S}_{3} \mathrm{P}_{3}$ in the process, preincubation with $10 \mu \mathrm{M}$ TY-52156 for $30 \mathrm{~min}$ substantially diminished P-selectin mobilization by S1P (Fig. 2a).

We then addressed the signalling pathways downstream of $\mathrm{S} 1 \mathrm{P} / \mathrm{S}_{1} \mathrm{P}_{3}$ responsible for $\mathrm{P}$-selectin mobilization. Phospholipase $\mathrm{C}$ (PLC) and $\mathrm{Ca}^{2+}$ are known to play a role in the exocytosis of Weibel-Palade bodies ${ }^{33}$, and S1P has been shown to activate PLC in $\mathrm{CHO}$ cells overexpressing $\mathrm{S}_{3} \mathrm{P}_{3}$ (ref. 34,35). Thus, we added the PLC inhibitor U73122 (3 $\mu \mathrm{M}) 2$ min before S1P stimulation and observed a clear reduction in P-selectin mobilization (Fig. 2b). To address the role of $\mathrm{Ca}^{2+}$, we depleted internal $\mathrm{Ca}^{2+}$ pools by adding thapsigargin $(3 \mu \mathrm{M})$ for $5 \mathrm{~min}$ before stimulation with $\mathrm{S} 1 \mathrm{P}$, while simultaneously preventing the extracellular $\mathrm{Ca}^{2+}$ influx by EGTA $(3 \mathrm{mM})$ added for the last minute. This treatment substantially suppressed P-selectin mobilization (Fig. 2b).

Although $\mathrm{S}_{1} \mathrm{P}_{3}$ couples to three $\mathrm{G}$ proteins $\left(\mathrm{G}_{\mathrm{q}}, \mathrm{G}_{\mathrm{i}}\right.$ and $\left.\mathrm{G}_{12 / 13}\right)$, the predominant signalling pathway it exercises is through $\mathrm{G}_{\mathrm{q}}$ (ref. 36). To test for an involvement of $G_{q}$ in leukocyte rolling in our model in general, we employed mice deficient for $\mathrm{G}_{\mathrm{q}}$ in endothelial cells on a global $\mathrm{G}_{11}$-deficient background $\left(G_{q / 11}-/- \text { mice }\right)^{37}$. We observed them to have a substantial reduction in leukocyte rolling (Fig. 2c). Administration of TY-52156 did not reduce rolling any further in $G_{q / 11}-/-$ mice (Fig. $2 c$ ), suggesting that under normal circumstances $\mathrm{S}_{1} \mathrm{P}_{3}$ enhances rolling through $\mathrm{G}_{\mathrm{q}}$.

FTY720 and S1P lyase blockade suppress rolling by impacting on $\mathrm{S1P}_{3}$. On the basis of our results so far, we hypothesized that downregulation of $\mathrm{S}_{3}$ by FTY720 would inhibit leukocyte rolling to a similar extent as does $\mathrm{S}_{1} \mathrm{P}_{3}$ deficiency or a $\mathrm{S}_{3} \mathrm{P}_{3}$ inhibitor. Furthermore, if $\mathrm{S}_{1} \mathrm{P}_{3}$ were the only receptor inducing P-selectin mobilization by S1P, FTY720 should not decrease rolling any further in $S 1 P_{3}^{-/}$mice. Indeed, administration of $1.25 \mathrm{mg}$ per $\mathrm{kg}$ FTY720 either $30 \mathrm{~min}$ or $24 \mathrm{~h}$ before the experiment dramatically attenuated leukocyte rolling (Fig. 3a). In agreement with our second hypothesis, we observed no additional inhibition of rolling by FTY720 in $S 1 P_{3}^{-/-}$mice (Fig. 3b). Finally, treatment with the S1P lyase inhibitor 4-deoxypyridoxine (DOP) that elevates plasma and tissue S1P and downregulates all $\mathrm{S} 1 \mathrm{P}$ receptors $^{38}$ also inhibited rolling (Fig. 3c). Rolling velocities did not differ significantly between the experimental groups (Supplementary Fig. 1), and P-selectin-mediated rolling was independent of putative DOP effects on plasma or leukocytes as no differences in rolling were observed on immobilized P-selectin (Supplementary Fig. 5)

We then went further to examine the effect of FTY720 on $\mathrm{P}$-selectin mobilization in vitro. Pretreatment of HUVEC with the active, phosphorylated form of FTY720 (pFTY720, $10 \mu \mathrm{M}$ for $30 \mathrm{~min}$ ) almost completely abolished S1P-induced mobilization of P-selectin (Fig. 3d). PhosphoFTY720 itself $(1 \mu \mathrm{M})$ had only a minor, almost negligible effect on P-selectin compared with $1 \mu \mathrm{M}$ S1P after $5 \mathrm{~min}$ and no effect at all after $30 \mathrm{~min}$ (a time when the S1P effect was still clearly visible; Fig. 3d). This may seem surprising in light of the agonistic effect of pFTY720 known for all $\mathrm{S} 1 \mathrm{P}$ receptors except $\mathrm{S}_{1} \mathrm{P}_{2}$ before their subsequent cell surface downregulation. However, we have previously shown that pFTY720 activates only the $G_{i}$ and not the $G_{q}$ signalling pathway of $\mathrm{S} \mathrm{P}_{3}$ and also inhibits $\mathrm{G}_{\mathrm{q}}$-transmitted $\mathrm{S}_{1} \mathrm{P}_{3}$ signalling by native $\mathrm{S}_{1} \mathrm{P}^{39}$. Here we observed something very similar in respect to P-selectin: addition of a 10-fold higher concentration of pFTY720 simultaneously with S1P resulted in a clear inhibition of S1P-induced P-selectin mobilization (Fig. 3d). In agreement, addition of S1P or pFTY720 for $30 \mathrm{~min}$ to another cellular system 
Table 1 | Haemodynamic parameters of mouse cremaster muscle experiments.

\begin{tabular}{|c|c|c|c|c|c|c|c|c|}
\hline Mouse strain & Treatment & Fig. & Mice $(n)$ & Venules & Diameter $(\mu \mathrm{m})$ & Centreline velocity $\left(\mu \mathrm{ms}^{-1}\right)$ & Shear rate $\left(s^{-1}\right)$ & WBC $\left(\times 10^{3} \mu I^{-1}\right)$ \\
\hline C57B16 & None & $1 a$ & 6 & 21 & $30.0 \pm 1.1$ & $1,876 \pm 215$ & $1,562 \pm 160$ & $5,704 \pm 622$ \\
\hline $\mathrm{STP}_{3}^{-1-}$ & & & 5 & 20 & $28.8 \pm 1.4$ & $1,885 \pm 182$ & $1,449 \pm 203$ & $8,060 \pm 983$ \\
\hline C57BI6 & None & 1c & 5 & 16 & $33.6 \pm 1.6$ & $2,181 \pm 324$ & $1,693 \pm 319$ & $6,659 \pm 192$ \\
\hline \multirow[t]{2}{*}{ C57B16 } & None & $1 d$ & 5 & 5 & $34.9 \pm 1.6$ & $1,638 \pm 406$ & $1,150 \pm 270$ & $5,032 \pm 613$ \\
\hline & S1P & & 5 & 5 & $34.0 \pm 1.8$ & $1,427 \pm 408$ & $1,006 \pm 248$ & $4,144 \pm 367$ \\
\hline C57BI6 & None & $2 c$ & 4 & 17 & $29.3 \pm 1.9$ & $2,635 \pm 195$ & $2,303 \pm 188$ & $5,633 \pm 254$ \\
\hline \multirow[t]{3}{*}{ C57B16 } & None & $3 a$ & 5 & 26 & $33.4 \pm 1.1$ & $2,017 \pm 163$ & $1,524 \pm 131$ & $7,043 \pm 899$ \\
\hline & FTY $30 \mathrm{~min}$ & & 6 & 36 & $34.3 \pm 0.8$ & $1,857 \pm 127$ & $1,380 \pm 94$ & $4,270 \pm 203$ \\
\hline & $F T Y 24 h$ & & 6 & 35 & $32.5 \pm 1.0$ & $1,540 \pm 100$ & $1,178 \pm 71$ & $1,110 \pm 152^{\star}$ \\
\hline \multirow[t]{2}{*}{ C57B16 } & None $^{\dagger}$ & $3 b$ & 6 & 21 & $30.0 \pm 1.1$ & $1,876 \pm 215$ & $1,562 \pm 160$ & $5,704 \pm 622$ \\
\hline & FTY $30 \mathrm{~min}$ & & 8 & 32 & $29.4 \pm 0.6$ & $2,419 \pm 203$ & $2,033 \pm 175$ & $7,147 \pm 343$ \\
\hline \multirow[t]{2}{*}{$S 1 P_{3}^{-/-}$} & None ${ }^{\dagger}$ & & 5 & 20 & $28.8 \pm 1.4$ & $1,885 \pm 182$ & $1,449 \pm 203$ & $8,060 \pm 983$ \\
\hline & FTY $30 \mathrm{~min}$ & & 5 & 19 & $29.2 \pm 0.6$ & $2,384 \pm 196$ & $2,014 \pm 185^{\star}$ & $6,998 \pm 937$ \\
\hline \multirow[t]{2}{*}{ C57BI6 } & None $e^{\ddagger}$ & $5 e$ & 5 & 26 & $33.4 \pm 1.1$ & $2,017 \pm 163$ & $1,524 \pm 131$ & $7,043 \pm 899$ \\
\hline & Forskolin & & 5 & 21 & $30.4 \pm 1.2$ & $2,143 \pm 163$ & $1,768 \pm 147$ & $3,382 \pm 579^{\star}$ \\
\hline S1PSCL-Cre-ERT Cre ${ }^{-}$ & None & $7 a$ & 9 & 32 & $30.1 \pm 0.8$ & $1,778 \pm 153$ & $1,465 \pm 127$ & $3,250 \pm 567$ \\
\hline $\mathrm{SIPSCL}_{1}^{\mathrm{SCre}-\mathrm{ERT}} \mathrm{Cre}^{+}$ & & & 9 & 35 & $29.1 \pm 0.6$ & $1,849 \pm 172$ & $1,546 \pm 136$ & $2,238 \pm 289$ \\
\hline \multirow[t]{2}{*}{ SIPSCL-Cre-ERT Cre ${ }^{-}$} & None $e^{\S}$ & $7 b$ & 9 & 32 & $30.1 \pm 0.8$ & $1,778 \pm 153$ & $1,465 \pm 127$ & $3,250 \pm 567$ \\
\hline & FTY720 & & 3 & 12 & $27.7 \pm 0.9$ & $1,675 \pm 209$ & $1,488 \pm 184$ & $2,280 \pm 742$ \\
\hline \multirow[t]{2}{*}{ STPSCL-Cre-ERT Cre ${ }^{+}$} & None $e^{\S}$ & & 9 & 35 & $29.1 \pm 0.6$ & $1,849 \pm 172$ & $1,546 \pm 136$ & $2,238 \pm 289$ \\
\hline & FTY720 & & 4 & 16 & $27.8 \pm 0.9$ & $2,237 \pm 232$ & $1,999 \pm 213$ & $3,015 \pm 459$ \\
\hline $\begin{array}{l}\text { †Data are identical to Fig. } \\
\text { †Data are identical to Fig. } \\
\text { §Data are identical to Fig. }\end{array}$ & $\begin{array}{l}\text { e control ('non } \\
\text { la ('none'). } \\
\text { 3a ('none'). } \\
7 \text { a ('none'). }\end{array}$ & & & & White bloc & & & \\
\hline
\end{tabular}

a

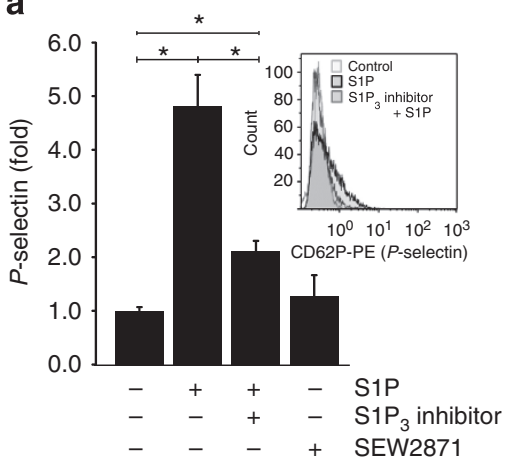

b

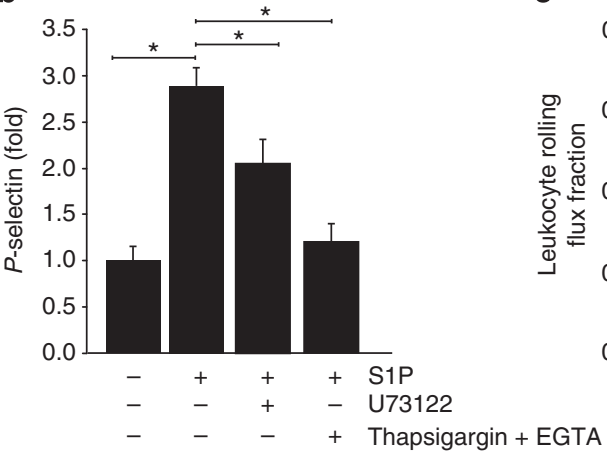

C

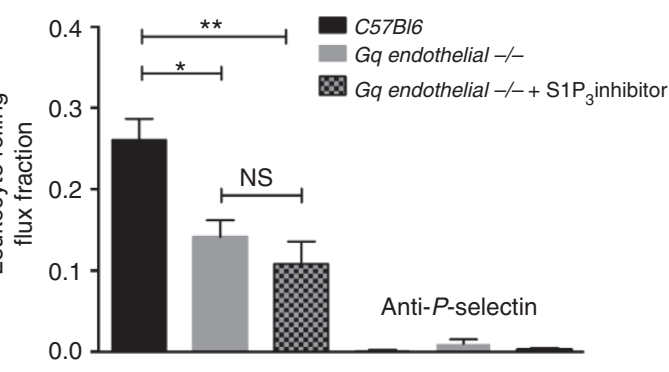

Figure 2 | S1P mobilizes P-selectin in endothelial cells and induces rolling through a $\mathbf{S 1 P}_{\mathbf{3}} / \mathbf{G}_{\mathbf{q}} / \mathbf{P L C} / \mathbf{C a}^{\mathbf{2}+}$ pathway. (a) HUVECs were stimulated with $\mathrm{S1P}(1 \mu \mathrm{M})$ for $5 \mathrm{~min}$ in the presence or absence of the S1P $\mathrm{P}_{3}$ inhibitor TY-52156 $(10 \mu \mathrm{M})$ or stimulated with the S1P agonist SEW2871 $(1 \mu \mathrm{M})$. P-selectin surface expression was analysed using flow cytometry. Data shown are from at least three independent experiments. Representative histogram is shown as inset. (b) HUVECs were stimulated with S1P $(1 \mu \mathrm{M})$ in the presence or absence of U73122 ( $3 \mu \mathrm{M}$ for 2 min) or thapsigargin ( $3 \mu \mathrm{M}$ for 5 min) in combination with EGTA ( $3 \mathrm{mM}$ for the last $1 \mathrm{~min}$ ). P-selectin was analysed using flow cytometry $5 \mathrm{~min}$ after the addition of S1P. Data shown are from at least three independent experiments. (c) Leukocyte rolling was quantified in postcapillary venules of the cremaster muscle of $G_{q / 11}-/-$ mice $(\mathrm{Gq}$ endothelial $-/-$ ) in the presence $(n=4)$ or absence $(n=5)$ of the $\mathrm{SPP}_{3}$ inhibitor TY-52156 $\left(1.25 \mathrm{mg} \mathrm{kg}^{-1}\right.$ i.p. $30 \mathrm{~min}$ before the experiment $)$ and in controls $(n=4)$. P-selectin-blocking antibody was injected to confirm complete dependence of rolling on P-selectin. Quantitative data are presented as mean \pm s.e.m. Significance was established using a paired two-tailed Student's $t$-test or a Kruskal-Wallis analysis of variance $(A N O V A)$ on ranks. ${ }^{\star} P<0.05$; ${ }^{\star \star} P<0.01$.

- $\mathrm{S}_{1} \mathrm{P}_{3}$-overexpressing $\mathrm{CHO}$ cells - followed by removal and subsequent (30 min later) $\mathrm{S} 1 \mathrm{P}$ stimulation abolished $\mathrm{S}_{1} \mathrm{P}_{3^{-}}$ dependent signalling such as Erk MAPK activation (Supplementary Fig. 6).
$\mathrm{S} \mathrm{P}_{3}$ conveys part of the P-selectin mobilization by histamine. P-selectin mobilization and consecutive leukocyte rolling in the trauma-stimulated cremaster muscle venules that we have examined here are known to be predominantly mediated by 

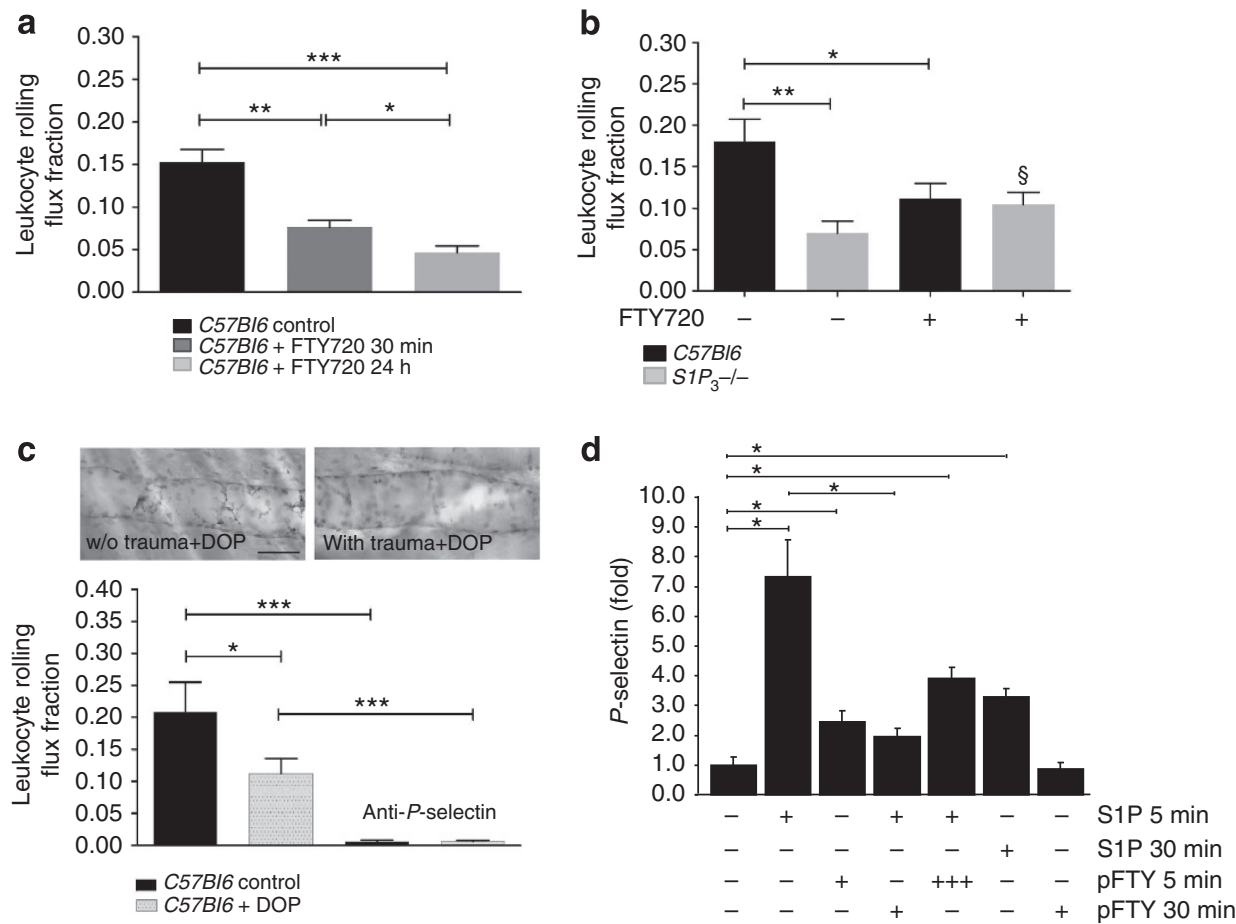

Figure 3 | FTY720 inhibit leukocyte rolling and P-selectin mobilization by S1P by interfering with S1P. Reduced rolling after S1P lyase inhibition. (a) Leukocyte rolling in C57BI6 mice treated without $(n=5)$ or with $1.25 \mathrm{mg} \mathrm{kg}^{-1}$ FTY720 i.p. either $30 \mathrm{~min}$ or $24 \mathrm{~h}(n=6$ each) before experiment. (b) Leukocyte rolling in C57BI6 $(n=8)$ and S1P- - - mice $(n=5)$ treated with $1.25 \mathrm{mg} \mathrm{kg}^{-1}$ i.p. FTY720 30 min before experiment. Untreated C57BI6 and S1P3 $-/-$ mice served for comparison $(n=6$ and 5). (c) Leukocyte rolling in C57BI6 mice treated with $(n=5)$ and without the S1P lyase inhibitor $\operatorname{DOP}(n=4)$. Top: whole-mount immunohistochemistry for P-Selectin after in vivo injection of an anti-P-selectin antibody shows the lack of P-selectin mobilization in the exteriorized traumatized cremaster (right) compared with the contralateral uninjured one (left). Scale bar, $40 \mu \mathrm{m}$. (d) HUVECs were stimulated with S1P $(1 \mu \mathrm{M})$ or pFTY720 $(1 \mu \mathrm{M})$ for 5 and 30 min with and without pFTY720 preincubation $(1 \mu \mathrm{M})$ for 30 min. In some experiments, pFTY720 $(10 \mu \mathrm{M})$ and S1P $(1 \mu \mathrm{M})$ were added simultaneously for $5 \mathrm{~min}$. ' $+++{ }^{\prime}$ indicates the 10 -fold higher pFTY720 concentration that was added simultaneously with S1P in this case. P-selectin surface expression was analysed by flow cytometry. Data are from three independent experiments. Quantitative data are presented as mean \pm s.e.m. Significance was established using a Kruskal-Wallis ANOVA on ranks or a Wilcoxon rank sum test, or a paired two-tailed Student's $t$-test $(\mathbf{d}) . P<0.05 ;{ }^{\star \star} P<0.01 ;{ }^{\star \star \star} P<0.001 ; \S<0.05$ between $S 1 P_{3}^{-/-}$and S1P ${ }_{3}^{-/}$with FTY720 in (b).

products of tissue mast cells activated upon mechanical manipulation during surgery ${ }^{29}$. Of these products, histamine accounts for approximately half of the effect on rolling as elegantly shown using $\mathrm{H} 1$ and $\mathrm{H} 2$ histamine receptor antagonists ${ }^{29}$. Recently, Sun et al. ${ }^{16}$ demonstrated that histamine superfusion of the cremaster muscle induces leukocyte rolling dependent on sphingosine kinase 1 (Sphk1), but the mechanism has remained unidentified. We asked the question whether $\mathrm{S}_{1} \mathrm{P}_{3}$ might be involved in histamine-induced P-selectin mobilization. To tackle this, we first titrated down the histamine concentration from $25 \mu \mathrm{M}$ (routinely used in the vast majority of the literature) to a 100 -fold lower concentration of $0.25 \mu \mathrm{M}$ (Fig. 4a). This much lower histamine concentration still leads to a substantial P-selectin mobilization in HUVEC within 5 min (Fig. 4a). The well-characterized sphingosine kinase inhibitor 4-[[4-(4chlorophenyl)-2-thiazolyl] amino]-phenol (SKi, $25 \mu \mathrm{M}$ (ref. 40)) suppressed P-selectin mobilization at both histamine concentrations, but was particularly effective at the lower one (Fig. 4a). Remarkably, administration of exogenous S1P in addition to SKi partially restored P-selectin mobilization by histamine (Fig. 4a), arguing for a S1P receptor conveying Sphk1mediated, histamine-dependent $\mathrm{P}$-selectin mobilization. We then tested whether the responsible $\mathrm{S} 1 \mathrm{P}$ receptor may be $\mathrm{S}_{1} \mathrm{P}_{3}$. Indeed, preincubation with the $\mathrm{S}_{3} \mathrm{P}_{3}$ inhibitor TY-52156 for $30 \mathrm{~min}$ dramatically reduced P-selectin mobilization by $0.25 \mu \mathrm{M}$ histamine (Fig. 4b). Thus, the reduction of histamine to lower and presumably more physiological concentrations in our model allowed us to assign part of its P-selectin-mobilizing effect to the engagement of $\mathrm{S}_{3}$ through endogenous Sphk1-generated S1P. Finally, we observed that leukocyte rolling was substantially reduced in cremaster muscle venules of Sphk1 $1^{-/-}$mice in vivo compared with C57Bl6 controls (Fig. 4c). Altogether, our data suggest that part of the histamine effect on P-selectin-mediated rolling is mediated by its activation of Sphk1, production of endogenous S1P and subsequent stimulation of P-selectin mobilization by endothelial $\mathrm{S}_{1} \mathrm{P}_{3}$.

cAMP induces $P$-selectin and rolling through $S p h k 1$ and $S_{1} P_{3}$. Several other agents besides histamine such as thrombin, vasopressin receptor agonists, purine nucleotides and epinephrine are well known to induce rapid P-selectin mobilization ${ }^{41}$. Many of them elevate intracellular cAMP through activation of the $\mathrm{G}_{\mathrm{s}}$ /adenylate cyclase (AC) pathway; however, the exact mechanisms leading to subsequent P-selectin mobilization are not entirely clear. In our hands, epinephrine $(9 \mu \mathrm{M})$ potently induced P-selectin mobilization in HUVEC (Fig. 5a). Remarkably, the $\mathrm{S}_{3} \mathrm{P}_{3}$ inhibitor TY-52156 substantially albeit not entirely suppressed epinephrine-induced P-selectin mobilization (Fig. 5a). Assuming that the cAMP/AC pathway is involved, we applied forskolin $(10 \mu \mathrm{M})$ as an established tool to directly stimulate AC. Indeed, forskolin potently mobilized P-selectin mobilization in HUVEC (Fig. 5b). Interestingly, this was clearly inhibited by $\mathrm{S}_{3} \mathrm{P}_{3}$ inhibitor TY-52156 (Fig. 5b). These 

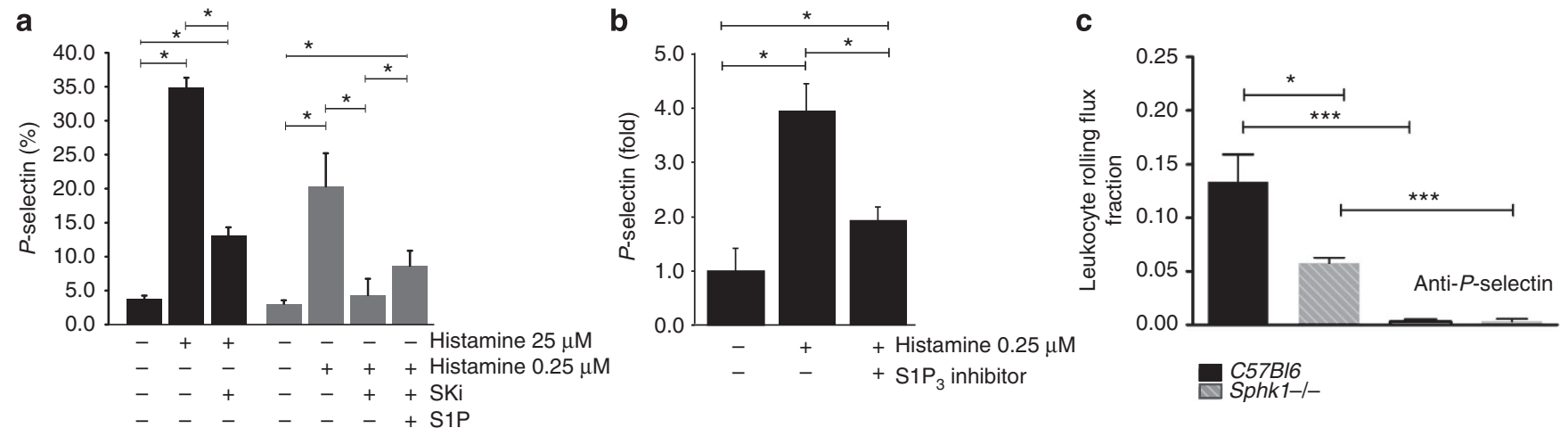

Figure 4 | S1P $\mathbf{S}_{\mathbf{3}}$ and Sphk1 mediate in part the effect of histamine on P-selectin mobilization and leukocyte rolling. (a) HUVECS were stimulated with two histamine concentrations $(0.25$ and $25 \mu \mathrm{M})$ in the presence or absence of SKi $(25 \mu \mathrm{M})$ or SKi + S1P $(1 \mu \mathrm{M})$ for 5 min as indicated, and cell surface P-selectin was measured by flow cytometry. Data shown are from three independent experiments. (b) HUVECs were stimulated with histamine ( $0.25 \mu \mathrm{M})$ in the presence or absence of the $\mathrm{S1P}_{3}$ inhibitor TY-52156 $(10 \mu \mathrm{M})$ and P-selectin was analysed by flow cytometry. Data are from five independent experiments. (c) Leukocyte rolling was quantified in postcapillary venules of the cremaster muscle of Sphk1 $1^{-/}$mice and controls ( $n=4$ per group). P-selectin-blocking antibody was injected to confirm rolling dependence on P-selectin. Quantitative data are presented as mean \pm s.e.m. Significance was established using a paired two-tailed Student's $t$-test or a Wilcoxon rank sum test. $P<0.05$; ${ }^{\star} P<0.05$; ${ }^{\star \star \star} P<0.001$.

data suggested that a mechanism involving AC activation and relying on $\mathrm{S}_{1} \mathrm{P}_{3}$ is in part responsible for P-selectin mobilization by cAMP-generating agents such as epinephrine and forskolin. Forskolin has been shown to activate Sphk1 in pheochromocytoma cells ${ }^{42}$. We thus hypothesized that this may be the case in endothelial cells as well. Thus, we determined enzymatic Sphk1 activity after forskolin stimulation by measuring the conversion of C17-sphingosine to C17-S1P using mass spectrometry. Indeed, C17-S1P production was clearly increased after forskolin $(10 \mu \mathrm{M})$ treatment of HUVEC for 30 min (Fig. 5c). To explore the consequences for $\mathrm{P}$-selectin mobilization, we employed forskolin and the nondegradable cAMP analogue cptcAMP, respectively, to activate Sphk and added the Sphk inhibitor SKi. Indeed, both forskolin $(10 \mu \mathrm{M})$ and cpt-cAMP $(0.3 \mathrm{mM})$ induced P-selectin mobilization, and in both cases SKi treatment substantially reduced it (Fig. 5d). Finally, we sought to reproduce these findings at the level of leukocyte rolling in vivo and applied forskolin $\left(1.3 \mathrm{mg} \mathrm{kg}^{-1}\right)$ intraperitoneally in our cremaster model. In agreement with its induction of P-selectin in vitro, forskolin clearly stimulated leukocyte rolling in vivo (Fig. 5e). In summary, these data have identified a novel cAMPdependent mechanism of P-selectin mobilization that acts through Sphk1 activation and employs subsequent $\mathrm{S}_{1} \mathrm{P}_{3}$ signalling.

Mast cell-derived S1P induces P-selectin in HUVEC via $\mathrm{S}_{\mathbf{P}}$. According to previous studies, histamine release from mast cells accounts for half of the leukocyte rolling in the cremaster model that by itself is completely mast cell-dependent ${ }^{29}$. Although S1P is not contained in mast cell granules, mast cell can release large amounts of S1P when allergically stimulated ${ }^{43-45}$. Thus, we hypothesized that tissue mast cells may be another source of S1P in our model thereby causing P-selectin mobilization and rolling. Physical stimuli such as pressure and temperature are known to induce mast cell activation in vitro and in vivo ${ }^{46,47}$. As surrogate for the physical stimulus of mechanical mast cell manipulation occurring during cremaster muscle exteriorization, we employed transient exposure of isolated peritoneal mast cells to a temperature of $53^{\circ} \mathrm{C}$ for $2 \mathrm{~min}$ as commonly employed to activate mast cell without adverse effects on viability ${ }^{46,47}$. We then added the mast cell supernatants immediately to HUVEC and measured P-selectin surface expression (Fig. 6). To exclude effects of histamine released under these conditions, we added diphenhydramine and cimetidine in concentrations sufficient to completely block P-selectin mobilization by $0.25 \mu \mathrm{M}$ histamine (Supplementary Fig. 4). The mast cell supernatants induced an impressive four- to fivefold increase in cell surface P-selectin expression compared with supernatants of unchallenged mast cells after $10 \mathrm{~min}$ (Fig. 6). Remarkably, this increase was suppressed by more than half by the $\mathrm{S}_{1} \mathrm{P}_{3}$ inhibitor TY-52156 (Fig. 6). Mass spectrometry of the identical supernatants revealed that S1P had been released $\left(90 \pm 41 \mathrm{pmol} \mathrm{S1P}\right.$ per $10^{6}$ mast cells) resulting in a $64.73 \pm 7.95 \mathrm{nM} \mathrm{S1P}$ concentration in the mast cell supernatants that the HUVEC had been exposed to. Another proof of biologically active S1P being present in the mast cell supernatants was their ability to activate Erk MAPK in $\mathrm{S}_{1} \mathrm{P}_{1}$ overexpressing $\mathrm{CHO}$ cells and the inhibition thereof by a $\mathrm{S}_{1} \mathrm{P}_{1}$ antagonist (Supplementary Fig. 7).

Rolling is increased in endothelial $\mathbf{S 1}_{\mathbf{1}}$ deficiency. Finally, we examined leukocyte rolling in mice deficient for the endothelial $\mathrm{S}_{1} \mathrm{P}_{1}$ receptor $\left(S 1 P_{1}^{S C L-C r e-E R T}\right)$ and observed it to be increased compared with respective controls (Fig. 7a). Furthermore, administration of FTY720 reduced rolling in $S 1 P_{1}^{S C L-C r e-E R T}$ mice to the same lower than basal levels observed with FTY720 in control mice and C57Bl6 mice, respectively, and $\mathrm{S}_{\mathrm{P}} \mathrm{P}_{3}^{-1}$ mice (Fig. 7b). Microvascular and haemodynamic parameters as well as rolling velocities were unaffected (Table 1 and Supplementary Fig. 1). Interestingly, the highly specific S1P 1 agonist AUI 954 (ref. 48) inhibited forskolin-induced C17-S1P generation in HUVEC in vitro along with inhibiting cAMP generation (Supplementary Fig. 8). These results suggest that $\mathrm{S}_{1} \mathrm{P}_{1}$ negatively regulates cAMPstimulated Sphk1 and by reducing S1P generation possibly inhibits P-selectin-dependent rolling, hence acting as an opponent to $\mathrm{S}_{1} \mathrm{P}_{3}$.

\section{Discussion}

Our study reveals the following six important and novel findings (Fig. 8): (1) we provide evidence that S1P is a direct agonist of P-selectin mobilization and leukocyte rolling; (2) we identify $\mathrm{S}_{3} \mathrm{P}_{3}$ as the major responsible S1P receptor; (3) we show that several P-selectin agonists employ S1P and $\mathrm{S} \mathrm{P}_{3}$ as mediators of their P-selectin-mobilizing effects by activating Sphk1; (4) we 

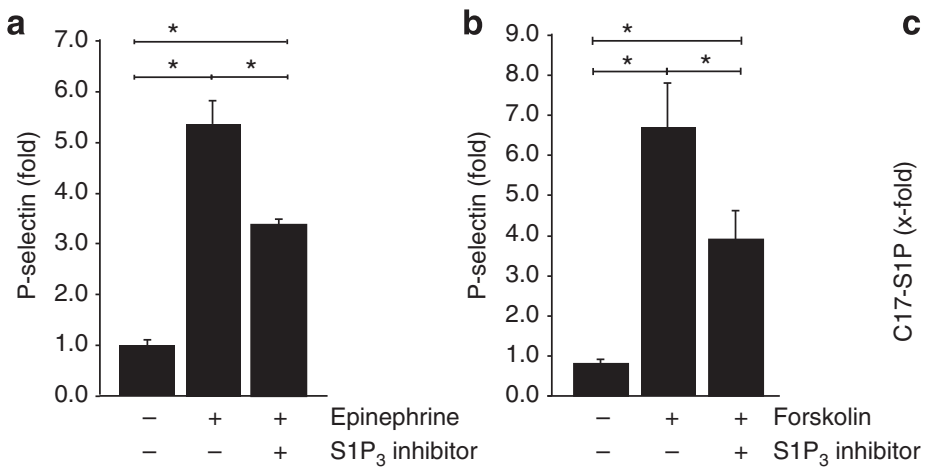

C

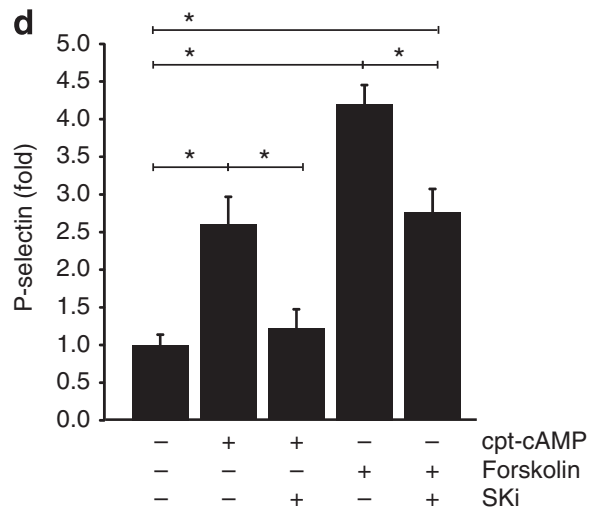

e
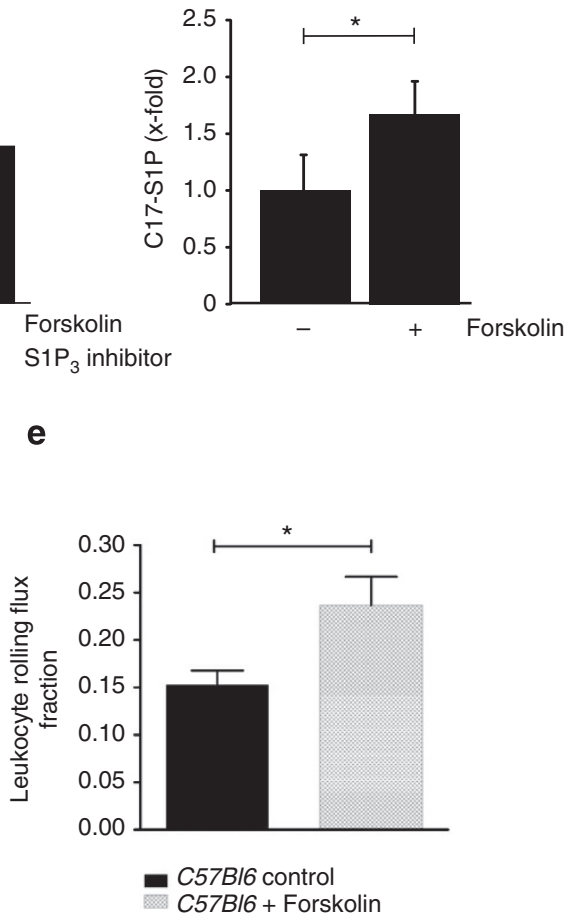

Figure 5 | Epinephrine and forskolin stimulate P-selectin mobilization and leukocyte rolling through adenylate cyclase/cAMP-dependent Sphk1 activation and engagement of $\mathbf{S 1 P}_{\mathbf{3}}$. HUVECs were stimulated with (a) epinephrine $(9 \mu \mathrm{M})$ in the presence of IBMX (100 $\left.\mu \mathrm{M}\right)$ and $(\mathbf{b})$ forskolin $(10 \mu \mathrm{M})$ with or without the $\mathrm{S}_{1} \mathrm{P}_{3}$ inhibitor TY-52156 $(10 \mu \mathrm{M})$, and P-selectin was analysed by flow cytometry. Data shown are from five independent experiments. (c) HUVECs were stimulated with forskolin $(10 \mu \mathrm{M})$ in the presence of C17-sphingosine for 30 min, washed and analysed for intracellular C17-S1P using mass spectrometry. Data shown are from four independent experiments. (d) HUVECs were stimulated with forskolin (10 $\mu \mathrm{M})$ or $\mathrm{cpt}-\mathrm{cAMP}(0.3 \mathrm{mM})$ in the presence or absence of SKi $(25 \mu \mathrm{M})$ for $30 \mathrm{~min}$. P-selectin was analysed by flow cytometry. Data shown are from five independent experiments. (e) Leukocyte rolling in C57B16 mice treated with forskolin or vehicle ( $n=5$ per group). Quantitative data are presented as mean \pm s.e.m. Significance was established using a paired two-tailed Student's $t$-test or a Wilcoxon rank sum test. ${ }^{\star} P<0.05$.

characterize a novel cAMP-dependent mechanism of Sphk1 activation and P-selectin mobilization; (5) we identify a rollinginhibitory effect of endothelial $\mathrm{S}_{1} \mathrm{P}_{1}$; and (6) we show that pharmacological inhibition or downregulation of $\mathrm{S}_{1} \mathrm{P}_{3}$ for example by FTY720 attenuates leukocyte rolling in a physiological setting. Only few studies have addressed S1P in the context of processes related to leukocyte rolling: (1) S1P has been demonstrated to both induce and inhibit the exocytosis of von Willebrand factor through different pathways ${ }^{49}$; (2) Sphk1 was suggested to play no role in basal leukocyte rolling but to promote rolling after exogenous histamine administration ${ }^{16} ;(3)$ although S1P promoted firm neutrophil adhesion in vitro ${ }^{50}$, neutrophil recruitment was inhibited during acute inflammatory lung injury in S1P lyase-deficient mice ${ }^{51}$, with S1P lyase inhibitors ${ }^{52}$ and by S1P administration ${ }^{53}$, respectively, and (4) FTY720 was shown to suppress neutrophil recruitment in several disease models ${ }^{3,53,54}$. This has made general conclusions on the role of S1P and its receptors in leukocyte rolling or their mode of action rather difficult.

Our findings add some new evidence that helps to better understand the role of S1P in rolling. First, it is crucial to distinguish acute S1P effects on pre-stored P-selectin occurring within minutes from S1P effects on cytokine-induced P-selectin transcription that takes hours. Second, the acute S1P effects on P-selectin are different from those caused by continuous exposure to high S1P levels or the lack of S1P receptors. Third, the effects of S1P analogues such as FTY720 may differ considerably from the effects of genuine S1P at the receptor level ${ }^{55}$. In respect to rapid P-selectin mobilization, we have clearly shown that S1P is a direct P-selectin agonist and leads to increased P-selectin-dependent leukocyte rolling within minutes of its direct administration into the circulation. It is known that despite the high amounts of S1P already present in the blood, intravascular injection of S1P can still cause functional effects on the endothelium such as attenuation of vascular leakage, vasodilatation and protection against reperfusion injury ${ }^{53,56,57}$. Accordingly, the reduced leukocyte rolling we observed after pharmacological $\mathrm{S}_{3} \mathrm{P}_{3}$ inhibition and in $\mathrm{S}_{3} \mathrm{P}_{3}{ }^{-/}$mice, respectively, are strong arguments for the causal and direct positive contribution of endothelial S1P signalling to P-selectin-dependent leukocyte rolling. However, we have also found evidence that endothelial $\mathrm{S}_{1} \mathrm{P}_{1}$ plays an opposite role in rolling as its deletion led to a rolling increase. However, the pro-rolling effect of $\mathrm{S} \mathrm{P}_{3}$ appears to be dominant over the anti-rolling effect of $\mathrm{S}_{1} \mathrm{P}_{1}$ as the net effect of acute intravascular S1P administration in wild-type mice (where both receptors are being engaged) was an overall increase in rolling. However, in the absence of $\mathrm{S}_{1} \mathrm{P}_{3}$, anti-rolling effects of $\mathrm{S}_{1} \mathrm{P}_{1}$ may also contribute to the reduction in rolling. In fact, there was a minor but significant increase in rolling with FTY720 in $\mathrm{S}_{3} \mathrm{P}_{3}$ deficiency that may have occurred because of $\mathrm{SP}_{1}$ downregulation by FTY720. Accordingly, in the absence of endothelial $\mathrm{S}_{1} \mathrm{P}_{1}$, the increase in rolling may be due to a combination of the loss of anti-rolling $\mathrm{S}_{1} \mathrm{P}_{1}$ effects and the still intact and potent pro-rolling $\mathrm{S}_{1} \mathrm{P}_{3}$ effects. Indeed, in $S 1 P_{1}^{-/-}$ mice, FTY720 inhibited rolling to lower than basal levels. 


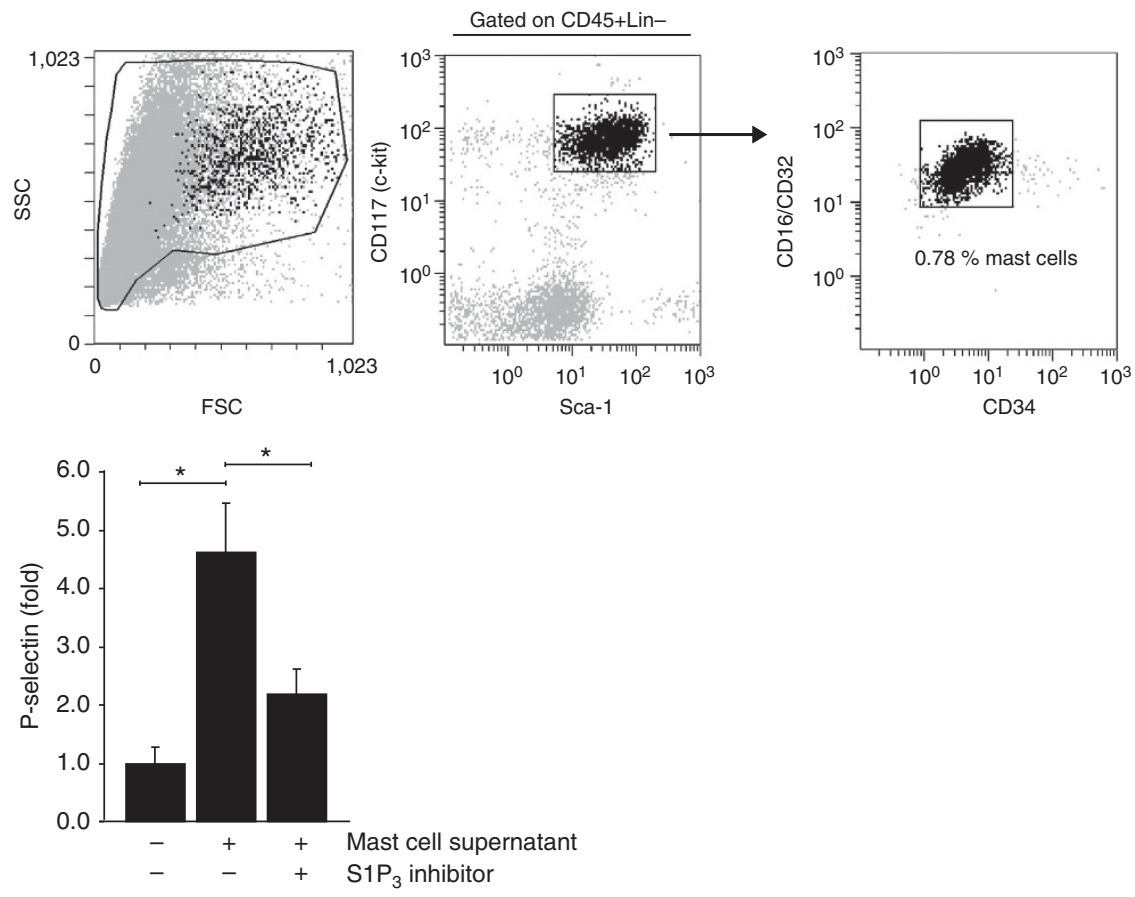

Figure 6 | Supernatants of activated mast cells stimulate P-selectin mobilization in HUVEC in a S1P $\mathbf{P}_{\mathbf{3}}$-dependent manner. (Top) FACS analysis of mouse peritoneal mast cells $\left(\mathrm{CD} 45^{+} \mathrm{Lin}^{-} \mathrm{CD} 117^{+} \mathrm{Sca}-1^{+} \mathrm{CD} 16 / 32^{+} \mathrm{CD} 34^{+}\right)$used for stimulation. (Bottom) HUVECs were stimulated with supernatants of heat-activated peritoneal mast cells for $10 \mathrm{~min}$ in the presence or absence or the $\mathrm{S}_{3} \mathrm{P}_{3}$ inhibitor TY-52156 $(10 \mu \mathrm{M})$. Diphenhydramine and cimetidine (10 $\mu \mathrm{M}$ each) were present in all experiments. P-selectin was measured using flow cytometry. Quantitative data are presented as mean \pm s.e.m. for three independent mast cell preparations and three independent HUVEC preparations. Significance was established using a paired two-tailed Student's $t$-test. $P<0.05$.

a

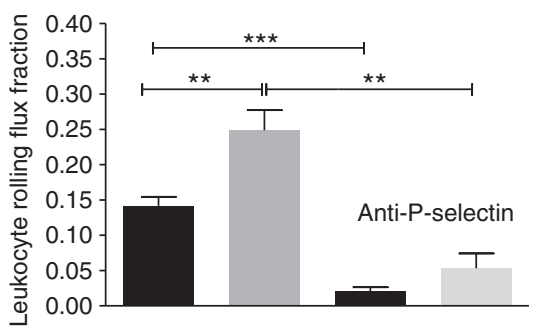

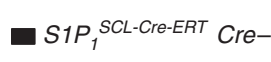

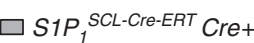

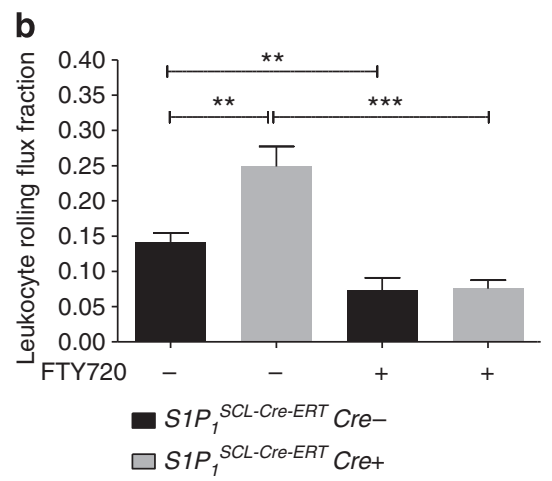

Figure 7 | Leukocyte rolling is increased in endothelial-specific S1P $\mathbf{1}$ knockout mice (S1P $\mathbf{~ S C L - C r e - E R T})$. (a) Leukocyte rolling was quantified in postcapillary venules of the cremaster muscle of $S 1 P_{1} S C L-C r e-E R T$ mice (Cre + and $\mathrm{Cre}-, n=9$ per group). Rolling was also measured after systemic injection of a P-selectin-blocking antibody ( $n=4$ per group). (b) Leukocyte rolling after administration of $1.25 \mathrm{mg} \mathrm{kg}^{-1}$ i.p. FTY720 $30 \mathrm{~min}$ before the experiment in both genotypes ( $\mathrm{Cre}+n=4$, Cre $-n=3$ ). Quantitative data are presented as mean \pm s.e.m. Significance was established using a Wilcoxon rank sum test. ${ }^{\star} P<0.05 ;{ }^{\star} P<0.05 ;{ }^{\star \star \star} P<0.001$.

We have identified two possible sources of endogenous S1P involved in P-selectin mobilization in our model: interstitial mast cells and endothelial cells (Fig. 8). Interstitial mast cell activation following mechanical cremaster muscle manipulation is entirely responsible for the leukocyte rolling occurring there, and histamine release accounts for $\sim 50 \%$ of it (ref. 29). As S1P can be released by allergically activated mast cells ${ }^{45}$, and physical stimuli such as pressure and heat can activate mast cells ${ }^{46,47}$, we hypothesized that S1P may be another mast cell product contributing to the remaining part of leukocyte rolling. The physical stimulus we employed to test this in mast cells was a short, harmless temperature elevation ${ }^{46,47}$. Indeed, we found them to release S1P within minutes that mobilized
P-selectin in HUVEC in part in a $\mathrm{S}_{1} \mathrm{P}_{3}$-dependent manner. Whether this occurs in vivo and actually contributes to leukocyte rolling in our model should be addressed by future studies. Although platelets are the major source of P-selectin, elaborate studies have shown that platelet P-selectin does not play a role in leukocyte rolling ${ }^{58,59}$, and, in our hands, S1P had no effect on basal or thrombin-stimulated P-selectin in platelets; neither was platelet activation altered in Sphk1 $1^{-1-}$ mice (Supplementary Fig. 9).

We have identified endothelial cells as the second source of endogenous S1P capable of inducing P-Selectin mobilization. Sphk1 activation has been known to occur after stimulation with inflammatory cytokines as well as histamine; however, the pathway 


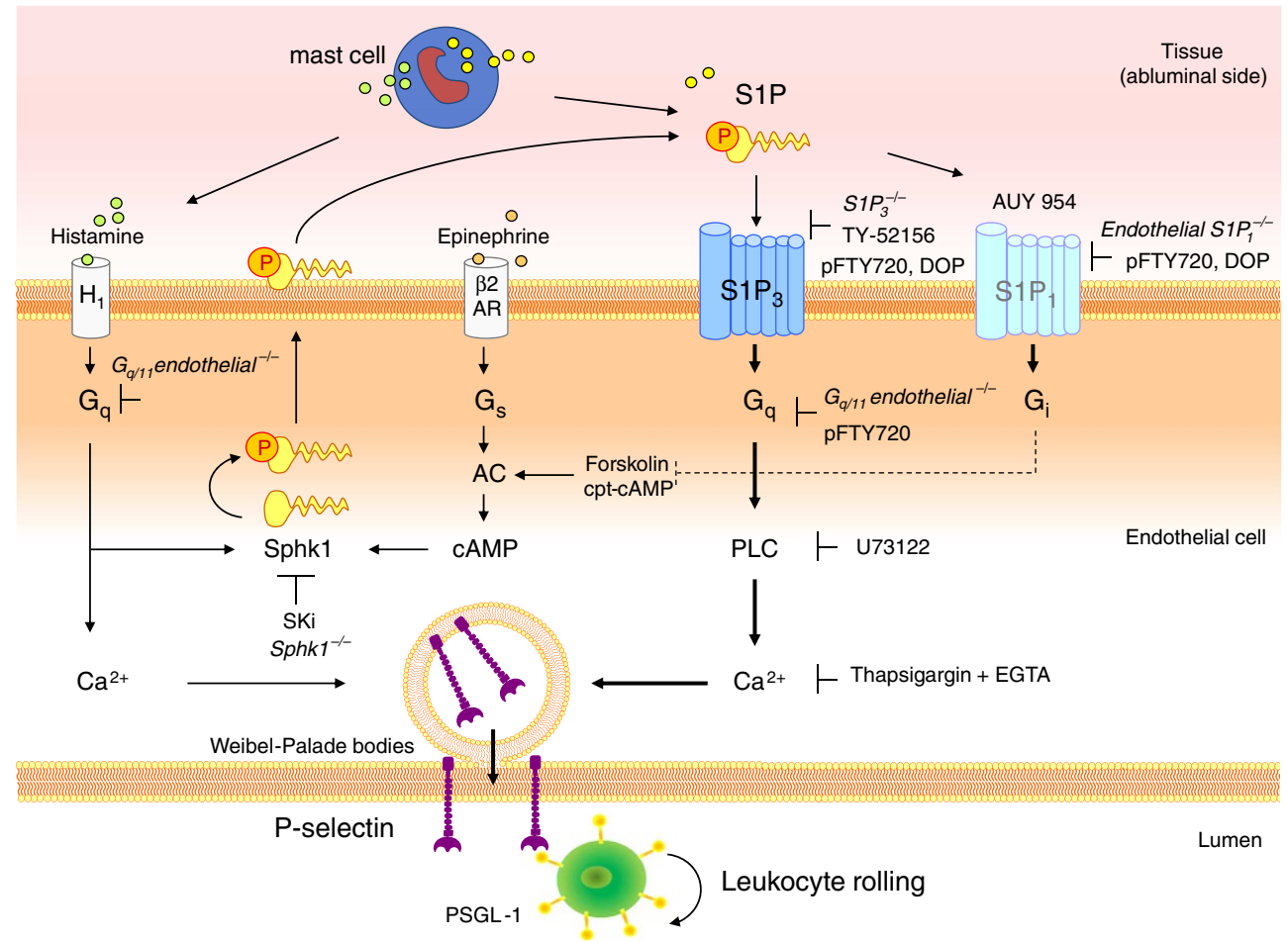

Figure 8 | The role of S1P and its receptors in P-Selectin mobilization. Schematic representation of the direct and indirect roles S1P plays in P-selectin mobilization. Mast cells release both histamine and S1P that can both mobilize P-selectin independently through the $\mathrm{H}_{1}$ and $\mathrm{S} 1 \mathrm{P}_{3}$ receptor, respectively. However, histamine achieves full scale P-selectin mobilization by additional Gq-dependent activation of Sphk1, S1P production/release and subsequent activation of S1P3. Other P-selectin mobilizing agents such as epinephrine that require CAMP for P-selectin mobilization also employ Sphk1 for full-blown effect but do so through a Gs/AC/cAMP-dependent pathway. S1P1 plays an inhibitory effect on P-selectin-dependent rolling by reducing AC-induced Sphk1 activity through $\mathrm{Gi}$. DOP and pFTY720 act in an inhibitory manner on rolling by downregulating S1P1 and S1P3, but in addition, pFTY720 directly inhibits the Gq-dependent part of S1P-incuded S1P3-dependent P-selectin mobilization. In summary, the pro-rolling effect of S1P3 dominates over the anti-rolling of $\mathrm{S1P}_{1}$, and the net effect of acute S1P exposure is an overall increase in P-selectin-dependent leukocyte rolling. AC, adenylate cyclase; AUY 954, S1P1-specific agonist; $\beta 2 A R, \beta 2$ adrenergic receptor; DOP, the S1P lyase inhibitor 4-deoxypyridoxine; $\mathrm{H} 1, \mathrm{H} 1$ histamine receptor; PSGL, P-selectin glycoprotein ligand-1; Sphk1, sphingosine kinase 1; TY-52156, S1P 3 -specific inhibitor.

by which it contributes to rolling has remained unclear $^{16}$. We provide evidence that S1P produced by histamine-activated Sphk1 contributes to full-blown histamine mobilization of P-selectin through $\mathrm{S}_{1} \mathrm{P}_{3}$. The evidence stems from two observations: (1) the partial inhibition of P-selectin mobilization after histamine by the blockade of Sphk1 or $\mathrm{S}_{3} \mathrm{P}_{3}$ and (2) the elimination of the inhibitory effect of Sphk1 blockade on P-selectin by exogenous S1P. Coincidently, the $\mathrm{S}_{1} \mathrm{P}_{3}$ receptor, the $\mathrm{H} 1$ histamine receptor and the thrombin PAR-1 receptor ${ }^{41}$ not only all mobilize P-selectin but also couple to $G_{q}$; on the other side, pharmacological $G_{q}$ inhibition has been shown to inhibit P-selectin exocytosis at least in platelets ${ }^{60}$. This offers a plausible explanation of why $\mathrm{S}_{1} \mathrm{P}_{3}$ effects have gone unnoticed in experiments employing $\mathrm{H} 1$ blockers or $\mathrm{G}_{\mathrm{q}}$ inhibitors. Our finding that endothelial-specific $G_{q / 11}-/-$ mice have reduced P-selectin-dependent leukocyte rolling can certainly be explained by the blockade of several $\mathrm{G}_{\mathrm{q}}$-coupled receptors including $\mathrm{S}_{1} \mathrm{P}_{3}$. Indeed, all these agonists have their own S1Pindependent pathways of inducing $\mathrm{P}$-selectin as neither $\mathrm{S}_{1} \mathrm{P}_{3}$ nor Sphk1 deletion/inhibition was able to completely inhibit P-selectin mobilization. However, part of the histamine effect can be attributed to $\mathrm{S}_{1} \mathrm{P}_{3}$. Our observation that rolling could not be reduced any further by pharmacological $\mathrm{S}_{1} \mathrm{P}_{3}$ inhibition in $\mathrm{G}_{\mathrm{q} / 11}-/-$ mice argues that $\mathrm{G}_{\mathrm{q}}$ mediates the pro-rolling effect of $\mathrm{S}_{1} \mathrm{P}_{3}$. The site of action of S1P released by interstitial mast cells or by endothelial cells exposed to histamine from the same mast cells would primarily be on the abluminal side of the vascular endothelium. This complies with an oriented signalling mode as the abluminal side should be reached first by any locally released interstitial agents. This scenario is in line with the dynamic signalling model proposed by Camerer et al. ${ }^{7}$ of how abluminal S1P signalling maintains endothelial integrity despite high S1P levels in blood.

We were also intrigued by the observation that not only histamine but another P-selectin-mobilizing agonist such as epinephrine ${ }^{41}$ that couples with $\mathrm{G}_{\mathrm{s}}$ and not $\mathrm{G}_{\mathrm{q}}$ employed Sphk1 and $\mathrm{S} \mathrm{P}_{3}$ for full-scale P-selectin mobilization (Fig. 8). We have demonstrated that epinephrine also activated Sphk1 but through a cAMP-dependent mechanism and - similar to histamine - also employed S1P and $\mathrm{S}_{1} \mathrm{P}_{3}$ to help mobilize P-selectin. Indeed, direct stimulation of Sphk1 by forskolin (as measured by the conversion of C17-sphingosine to C17-S1P) mobilized P-selectin through $\mathrm{S}_{3} \mathrm{P}_{3}$ in vitro and induced leukocyte rolling in vivo. In agreement with a role for cAMP, forskolin has been shown to activate Sphk1 in pheochromocytoma cells years ago ${ }^{42}$. However, $\mathrm{S}_{1} \mathrm{P}_{3}$ or Sphk1 inhibition did not completely abrogate the effects of epinephrine or forskolin, suggesting that there must be additional pathways of how cAMP mobilizes P-selectin ${ }^{41}$. Interestingly, the pathway of cAMP-stimulated Sphk1 provides a putative mechanism of how $\mathrm{S}_{1} \mathrm{P}_{1}$, with its established inhibitory effect on cAMP generation ${ }^{4}$, may be exerting its antirolling effect. Indeed, the highly specific $\mathrm{S} 1 \mathrm{P}_{1}$ agonist AUI 954 (ref. 48) inhibited C17-S1P generation after forskolin along with lowering cAMP (Supplementary Fig. 8). This suggests that $\mathrm{S}_{1} \mathrm{P}_{1}$ may be attenuating cAMP-induced Sphk1 activation in a negative-feedback manner, thereby restricting the 
amounts of S1P available for P-selectin mobilization by $\mathrm{S}_{1} \mathrm{P}_{3}$. The reduced leukocyte rolling we have observed in $S p h k 1^{-1-}$ mice is in line with Sphk1/S1P serving as a general transmission/ amplification hub for different incoming P-selectin mobilization signals. While the $\mathrm{S}_{1} \mathrm{P}_{1}$ receptor has often been implicated in Sphk1 signalling, there is to our knowledge only scarce evidence for an involvement of $\mathrm{S}_{1} \mathrm{P}_{3}$ in conveying Sphk1 signals: only one study has implied $\mathrm{S}_{1} \mathrm{P}_{3}$ as a mediator of thrombin-induced Sphk1 effects in dendritic cells ${ }^{61}$. The requirement of $\mathrm{S}_{3} \mathrm{P}_{3}$ for full efficiency of several P-selectin agonists may also serve another purpose: $\mathrm{S}_{1} \mathrm{P}_{3}$ downregulation or desensitization after engagement by endogenous S1P may help ameliorate excessive P-selectin stimulation and help turn it off.

Acute S1P effects on P-selectin mobilization should be distinguished from those caused by continuous exposure to S1P or S1P analogues. High S1P levels after S1P lyase inhibition or deficiency and administration of FTY720 have been shown to downregulate $\mathrm{S} 1 \mathrm{P}$ receptors ${ }^{1,62,63}$ including $\mathrm{S} \mathrm{P}_{3}$ (ref. 64) and impair lymphocyte trafficking. Accordingly, the reduced neutrophil recruitment found in S1P lyase-deficient mice ${ }^{51}$ or after FTY720 treatment ${ }^{53,54}$ may be due to downregulation of $\mathrm{S}_{1} \mathrm{P}_{3}$. In line with this, we have observed that FTY720 had no additional inhibitory effect on rolling in $\mathrm{S}_{3} \mathrm{P}_{3}^{-1-}$ mice. However, another mechanism may also be involved: we have previously shown that pFTY720 is a potent inhibitor of $\mathrm{G}_{\mathrm{q}^{-}}$mediated S1P-induced $\mathrm{SiP}_{3}$ signalling ${ }^{39}$. In the present study, we extended this observation to P-selectin mobilization by $\mathrm{S}_{3} \mathrm{P}_{3}$. Thus, both mechanisms could be taking place simultaneously as: (1) preincubation with pFTY720 abolished S1P-induced $\mathrm{P}$-selectin mobilization in endothelial cells as well as $\mathrm{S}_{1} \mathrm{P}_{3^{-}}$ dependent S1P signalling in $\mathrm{S}_{3}-\mathrm{CHO}$ cells; (2) pFTY720 had a minor and very short-lived positive effect on P-selectin compared with S1P, while (3) its simultaneous application together with S1P abolished P-selectin mobilization by S1P. In line with this interpretation, another P-selectin-dependent process, the recruitment of early thymic progenitors to the thymic endothelium, has been shown to be inhibited by FTY720 (ref. 65), although the responsible receptor was not identified.

In summary, our study suggests an important role for S1P and $\mathrm{S}_{1} \mathrm{P}_{3}$ in the induction of rapid endothelial P-selectin mobilization and consecutive P-selectin-dependent leukocyte rolling. S1P acts thereby both directly as an agonist and, indirectly, as a contributor to P-selectin mobilization by other P-selectin agonists.

\footnotetext{
Methods

Mice. $\mathrm{S}_{1} \mathrm{P}_{3}^{-/-}$mice were provided by Jerold Chun, Scripps Research Institute to B.L. and crossbred to C57Bl6J for more than six generations. Sphk1 ${ }^{-/-}$mice were provided to M.H.G. by Richard Proia (NIH) and Tie2-Cre-ER(T2); Go flox/flox; $G \alpha_{11}-/-$ were from S.O. Mice deficient for the endothelial $\mathrm{S}_{1} \mathrm{P}_{1}$ receptor were

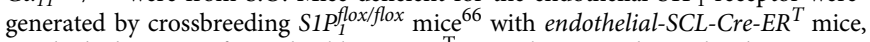
in which the tamoxifen-inducible Cre-ER ${ }^{\mathrm{T}}$ recombinase is driven by the $5^{\prime}$-endothelial enhancer of the stem cell leukaemia (SCL) locus ${ }^{67}$ (Supplementary Fig. 11). Cre-negative $S 1 P_{1}^{S C L-C r e-E R T}$ littermates treated with the same tamoxifen regimen were used as controls. Recombination was induced by daily intraperitoneal injections of tamoxifen ( $40 \mathrm{mg}$ per $\mathrm{kg}$ body weight) for five consecutive days, and the experiments were performed 6 weeks later. Successful recombination was shown in lung endothelial cells isolated using CD31-coated magnetic beads (Dynabeads) by site-specific PCR for the excised exon. All mice used in the study were male and at least 10 weeks of age. All procedures were performed in accordance with the institutional guidelines for health and care of experimental animals and were approved by the Regierung von Baden Württemberg and Oberbayern, respectively.
}

Substances and antibodies. S1P was purchased from Enzo Life Science. The $\mathrm{S}_{1} \mathrm{P}_{3}$ inhibitors TY-52156 (Supplementary Fig. 2) and FTY720 were synthesized as described $^{32}$. AUY 954 was a kind gift from Klaus Seuwen (Novartis). In vivo, FTY720 and TY-52156 were applied intraperitoneally at $1.25 \mathrm{mg}$ per $\mathrm{kg}$ and forskolin at $1.3 \mathrm{mg}$ per $\mathrm{kg}$ body weight $30 \mathrm{~min}$ or $24 \mathrm{~h}$ before the experiment as indicated. S1P was injected via a carotid artery catheter at $30 \mu \mathrm{g}$ per kg body weight $(125 \mu \mathrm{M}$ S1P solution in $2 \% \mathrm{BSA}$ per $0.9 \% \mathrm{NaCl})$. The S1P lyase inhibitor DOP (Sigma Aldrich) was supplemented in the drinking water $\left(30 \mathrm{mgl}^{-1}\right)$ for 1 week. W146 and C17 sphingosine were from Avanti polar lipids, the SKi 4-[[4-(4-chlorophenyl)-2-thiazolyl]amino]-phenol (SKi, SKI II and SPHK I2), pFTY720, SEW2871 and U73122 from Cayman Chemical Co; epinephrine from Sanofi Aventis; forskolin from Calbiochem; IBMX, cpt-cAMP, diphenhydramine and cimetidine from Sigma Aldrich; and thapsigargin from AppliChem. $\mathrm{S} \mathrm{P}_{1}-\mathrm{CHO}$ and $\mathrm{S}_{1} \mathrm{P}_{3}-\mathrm{CHO}$ cells were from Novartis. The following antibodies were used: CD62P-PE (phycoerythrin) anti-mouse (eBioscience, 12-0626-82, 3:100), CD4-PE anti-mouse (eBioscience, 12-0041, 1:100), CD8-PE anti-mouse (eBioscience, 12-0081, 1.4:100), Ter119-PE anti-mouse (Miltenyi, 130-091-783, 3:100), Ly6G\&Ly6C-PE anti-mouse (BD Pharmingen, 553128, 1.6:100), CD45R-PE anti-mouse (BD Pharmingen, 553089, 1.6:100), CD34-AlexaFluor700 anti-mouse (BD Pharmingen, 1.6:100), CD16/32-PerCpCy5.5 anti-mouse (BD Pharmingen, 560540, 1.65:100), LyA/E-FITC anti-mouse (BD Pharmingen, 557405, 1.1:100), CD117-PE-Cy7 anti-mouse (BD Pharmingen, 558163, 1.7:100), CD450-V450 anti-mouse (BD Pharmingen, 560697, 1.8:100) and P-selectin glycoprotein ligand1-PE anti-mouse (BD Pharmingen, 555306, 1:1,000). The P-selectin-blocking rat-anti-mouse monoclonal antibody RB40.34 was a generous gift from Dietmar Vestweber (MPI Münster).

Flow chamber assay for rolling on immobilized P-selectin. Rectangular glass capillaries $(0.4 \times 0.04 \mathrm{~mm}$, VitroCom) were used for ex vivo flow chamber experiments as described ${ }^{31}$. Chambers were coated with recombinant murine (rm)P-selectin (CD62-P, $20 \mu \mathrm{g} \mathrm{ml}^{-1}$, R\&D Systems). Following overnight incubation at $4{ }^{\circ} \mathrm{C}$, flow chambers were blocked with $5 \%$ casein (Sigma-Aldrich) in PBS for $2 \mathrm{~h}$. For experiments, one end of the chamber was attached to a carotid artery catheter, while the other was left open to regulate blood flow through the microflow chamber. Microscopy was performed using a modified Olympus BX51 upright microscope (LaVision Biotec) with a saline immersion objective (40/0.8 numerical aperture (NA), Olympus). Leukocyte rolling was recorded over $10 \mathrm{~min}$ per microflow chamber with a CCD (charge-coupled device) video camera (model CF8/1; Kappa) connected to a Panasonic S-VHS recorder and analysed offline.

Intravital microscopy of the cremaster muscle. Intravital microscopy of postcapillary venules of the mouse cremaster muscle was used to study leukocyte rolling under different inflammatory conditions ${ }^{25,27}$. Briefly, mice were anaesthetized by intraperitoneal injection of ketamine and xylazine (100 and $20 \mathrm{mg}$ per kg body weight, respectively), after which a tracheal tube was inserted and the carotid artery cannulated for blood sampling and systemic application of substances. Thereafter, the scrotum was opened, the cremaster muscle exteriorized, spread over a cover glass and superfused with warmed $\left(35^{\circ} \mathrm{C}\right)$ bicarbonate-buffered saline. Observation of postcapillary venules was conducted on an upright microscope (Olympus BX51) with a saline immersion objective ( $\times 40 / 0.8 \mathrm{NA}$ ). To abolish P-selectin-dependent rolling, the P-selectin-blocking monoclonal antibody RB40.34 (30 $\mu \mathrm{g}$ per mouse) was diluted in $200 \mu \mathrm{l}$ saline and injected via the carotid artery catheter. Experiments were recorded via a CCD camera system (model CF8/1; Kappa) on a Panasonic $\mathrm{S}$-VHS recorder. Systemic blood samples $(10 \mu \mathrm{l})$ were obtained before and during the experiment, stained using Turck's solution and assessed for white blood cell count using a haemocytometer. Data analysis was performed offline using the video tapes from in vivo experiments. Diameter, segment length of postcapillary venules and venular centreline blood flow velocity were assessed using a digital imageprocessing system and a digital online cross-correlation programme, respectively (Circusoft Instrumentation) ${ }^{24}$. Leukocyte rolling flux fraction was calculated from the number of rolling cells that crossed a perpendicular line through a given vessel within $1 \mathrm{~min}$ in relation to the total number of circulating leukocytes.

Whole-mount immunohistochemistry. For immunohistochemical detection of luminal endothelial P-selectin expression in cremaster muscle whole mounts, primary monoclonal antibody against P-selectin RB40.34 (30 $\mu \mathrm{g}$ per mouse) was systemically injected after 20-min superfusion of the exteriorized right cremaster muscle ensuring binding to P-selectin on the luminal vessel surface. To remove excess antibody, the inferior vena cava was cut and animals were perfused with $10 \mathrm{ml}$ of $0.9 \% \mathrm{NaCl}$. The left cremaster muscle was exteriorized post mortem to serve as unstimulated negative control. The cremaster muscles were then mounted on adhesive slides (Superfrost), transferred into $-20^{\circ}$ acetone over night and stored at $-80^{\circ} \mathrm{C}$ until further processing. For staining of P-selectin expression, cremaster whole mounts were permeabilized with saponin ( $0.03 \%$ in Tris-buffer) and incubated with $2 \mu \mathrm{g} \mathrm{ml}^{-1}$ biotinylated secondary goat anti-rat IgG (Southern Biotechnology Associates Inc, Cat. No 3030-08). Detection of antigen-antibody complexes was carried out with a commercial biotinylated horseradish peroxidase/ avidin complex (Vectastain ABC, Vector Laboratories) according to the manufacturer's instructions. Slides were counterstained using Mayer's Hemalaun and analysed using a Zeiss microscope with a $\times 100,1.4$ NA oil immersion objective.

P-selectin mobilization in HUVEC. HUVECs (passage 1-4) were cultured in $20 \%$ human serum/RPMI. After incubation in serum-free medium for $4 \mathrm{~h}$, cells were stimulated with histamine $(0.25$ or $25 \mu \mathrm{M})$, S1P $(1 \mu \mathrm{M})$, SEW2871 $(1 \mu \mathrm{M})$ and 
epinephrine $(9 \mu \mathrm{M}) / \mathrm{IBMX}(100 \mathrm{nM})$, respectively, for the indicated times. Before histamine or S1P stimulation, the $\mathrm{S}_{1} \mathrm{P}_{3}$ inhibitor TY-52156, SKi or phosphorylated FTY720 $(10 \mu \mathrm{M})$ were added for $30 \mathrm{~min}$; with forskolin, inhibitors were added $10 \mathrm{~min}$ before stimulation. Five minutes before the end of the experiment, PEconjugated anti-P-selectin antibody (eBioscience; 1.6:100) was added directly into the $500 \mu \mathrm{l}$ of incubation medium after which the cells were washed twice and analysed immediately by flow cytometry.

Stimulation with supernatants of activated mast cells. Mouse peritoneal mast cells were isolated by a Percoll gradient as described ${ }^{68}$ and characterized as $\mathrm{CD}^{+} 5^{+}, \mathrm{Lin}^{-}$(CD45R, Ly6G, Ly6C, Ter119, CD4 and CD8), CD117 ${ }^{+}, \mathrm{Sca}-1^{+}$, $\mathrm{CD} 16 / 32^{+}$and $\mathrm{CD} 34^{+}$cells by flow cytometry and consecutive toluidine blue staining ${ }^{68,69}$. The yield was $0.05-0.1 \times 10^{6}$ mast cells per mouse. All peritoneal cells were incubated with $10 \mu \mathrm{M}$ sphingosine for $30 \mathrm{~min}$ at $37^{\circ} \mathrm{C}$ before the Percoll gradient isolation procedure. Stimulation was performed by adding $250 \mu \mathrm{l}$ warm $\left(53^{\circ} \mathrm{C}\right) 2 \% \mathrm{BSA} / \mathrm{alphaMEM}$ to $0.5 \times 10^{6}$ mast cells and subsequent incubation for 2 min at $53^{\circ} \mathrm{C}$ as described ${ }^{46,47}$. For stimulation of HUVEC, $100 \mu$ l of the mast cell supernatant was supplemented with diphenhydramine and cimetidine $(10 \mu \mathrm{M}$ each) and added to confluent HUVEC cultured in $200 \mu \mathrm{l}$ RPMI for $10 \mathrm{~min}$. PEconjugated anti-P-selectin antibody was added directly into the $300 \mu \mathrm{l}$ at the time of stimulation. Cells were washed twice with serum-free medium, trypsinized and analysed by flow cytometry.

Measurements of Sphk1 activity using C17-sphingosine. Five $\mu \mathrm{M}$ C17-sphingosine was added together with $10 \mu \mathrm{M}$ forskolin to HUVEC in RPMI with $2 \mathrm{mg}$ per $\mathrm{ml} \mathrm{BSA}$ fraction V (Serva) for $30 \mathrm{~min}$. Cells were washed extensively and lysed in $50 \mathrm{mM}$ Tris/HCl (pH 7.5), $0.5 \% \mathrm{NP}-40,10 \%$ glycerol, $250 \mathrm{mM} \mathrm{NaCl}, 5 \mathrm{mM}$ EDTA, $0.5 \mathrm{mM}$ phenylmethyl sulphonyl fluoride, $5 \mathrm{\mu g} \mathrm{ml}^{-1}$ leupeptin and aprotinin. Protein concentration was measured using the Pierce BCA Protein Assay Kit (Thermo Scientific). C17-S1P was determined by mass spectrometry as described ${ }^{70}$ and expressed per milligram cell protein.

Statistics. For pair-wise comparison between experimental groups, a Wilcoxon rank sum test or paired Student's $t$-test was performed. For multiple comparisons, a Kruskal-Wallis nonparametric analysis of variance on ranks was performed followed by Dunn's post hoc test. A $P$ value $<0.05$ was considered statistically significant. All statistical analyses were carried out with GraphPad Prism 5.2 (PraphPad Software Inc, La Jolla). Data are presented as mean \pm s.e.m. Sample size has been provided for each experiment in the figure legend (no exclusion criteria, randomization or blinding).

\section{References}

1. Rivera, J., Proia, R. L. \& Olivera, A. The alliance of sphingosine-1-phosphate and its receptors in immunity. Nat. Rev. Immunol. 8, 753-763 (2008).

2. Ledgerwood, L. G. et al. The sphingosine 1-phosphate receptor 1 causes tissue retention by inhibiting the entry of peripheral tissue $\mathrm{T}$ lymphocytes into afferent lymphatics. Nat. Immunol. 9, 42-53 (2008).

3. Keul, P. et al. Sphingosine-1-phosphate receptor 3 promotes recruitment of monocyte/macrophages in inflammation and atherosclerosis. Circ. Res. 108, 314-323 (2010).

4. Rivera, R. \& Chun, J. Biological effects of lysophospholipids. Rev. Physiol. Biochem. Pharmacol. 160, 25-46 (2008).

5. McVerry, B. J. \& Garcia, J. G. In vitro and in vivo modulation of vascular barrier integrity by sphingosine 1-phosphate: mechanistic insights. Cell Signal. 17, 131-139 (2005)

6. Tauseef, M. et al. Activation of sphingosine kinase-1 reverses the increase in lung vascular permeability through sphingosine-1-phosphate receptor signaling in endothelial cells. Circ. Res. 103, 1164-1172 (2008).

7. Camerer, E. et al. Sphingosine-1-phosphate in the plasma compartment regulates basal and inflammation-induced vascular leak in mice. J. Clin. Invest. 119, 1871-1879 (2009).

8. Xia, P. et al. Tumor necrosis factor-alpha induces adhesion molecule expression through the sphingosine kinase pathway. Proc. Natl Acad. Sci. USA 95, 14196-14201 (1998)

9. Kimura, T. et al. Sphingosine 1-phosphate receptors mediate stimulatory and inhibitory signalings for expression of adhesion molecules in endothelial cells. Cell Signal. 18, 841-850 (2006).

10. Krump-Konvalinkova, V. et al. Stable knock-down of the sphingosine 1phosphate receptor S1P1 influences multiple functions of human endothelial cells. Arterioscler. Thromb. Vasc. Biol. 25, 546-552 (2005).

11. Limaye, V. et al. Chronic increases in sphingosine kinase-1 activity induce a pro-inflammatory, pro-angiogenic phenotype in endothelial cells. Cell Mol. Biol. Lett. 14, 424-441 (2009).

12. Kimura, T. et al. Role of scavenger receptor class B type I and sphingosine 1phosphate receptors in high density lipoprotein-induced inhibition of adhesion molecule expression in endothelial cells. J. Biol. Chem. 281, 37457-37467 (2006).
13. Bolick, D. T. et al. Sphingosine-1-phosphate prevents tumor necrosis factor\{alpha\}-mediated monocyte adhesion to aortic endothelium in mice. Arterioscler. Thromb. Vasc. Biol. 25, 976-981 (2005).

14. Whetzel, A. M. et al. Sphingosine-1 phosphate prevents monocyte/endothelial interactions in type 1 diabetic NOD mice through activation of the S1P1 receptor. Circ. Res. 99, 731-739 (2006).

15. Sattler, K. \& Levkau, B. Sphingosine-1-phosphate as a mediator of high-density lipoprotein effects in cardiovascular protection. Cardiovasc. Res. 82, 201-211 (2009).

16. Sun, W. Y. et al. Rapid histamine-induced neutrophil recruitment is sphingosine kinase-1 dependent. Am. J. Pathol. 180, 1740-1750 (2012).

17. Sperandio, M., Gleissner, C. A. \& Ley, K. Glycosylation in immune cell trafficking. Immunol. Rev. 230, 97-113 (2009).

18. Sperandio, M., Pickard, J., Unnikrishnan, S., Acton, S. T. \& Ley, K. Analysis of leukocyte rolling in vivo and in vitro. Methods Enzymol. 416, 346-371 (2006).

19. Ley, K. The role of selectins in inflammation and disease. Trends Mol. Med. 9, 263-268 (2003).

20. Rossi, B. \& Constantin, G. Anti-selectin therapy for the treatment of inflammatory diseases. Inflamm. Allergy Drug Targets 7, 85-93 (2008).

21. Impellizzeri, D. \& Cuzzocrea, S. Targeting selectins for the treatment of inflammatory diseases. Expert Opin. Ther. Targets 18, 55-67 (2014).

22. Luo, W. et al. P-selectin glycoprotein ligand-1 inhibition blocks increased leukocyte-endothelial interactions associated with sickle cell disease in mice. Blood 120, 3862-3864 (2012).

23. Combes, V. et al. Pathogenic role of P-selectin in experimental cerebral malaria: importance of the endothelial compartment. Am. J. Pathol. 164, 781-786 (2004).

24. Sperandio, M. et al. Alpha 2,3-sialyltransferase-IV is essential for L-selectin ligand function in inflammation. Eur. J. Immunol. 36, 3207-3215 (2006).

25. Klinke, A. et al. Myeloperoxidase attracts neutrophils by physical forces. Blood 117, 1350-1358 (2010).

26. Rivera-Nieves, J. et al. Critical role of endothelial P-selectin glycoprotein ligand 1 in chronic murine ileitis. J. Exp. Med. 203, 907-917 (2006).

27. Kunkel, E. J. et al. Absence of trauma-induced leukocyte rolling in mice deficient in both P-selectin and intercellular adhesion molecule 1. J. Exp. Med. 183, 57-65 (1996).

28. Mayadas, T. N., Johnson, R. C., Rayburn, H., Hynes, R. O. \& Wagner, D. D. Leukocyte rolling and extravasation are severely compromised in P selectindeficient mice. Cell 74, 541-554 (1993).

29. Kubes, P. \& Kanwar, S. Histamine induces leukocyte rolling in postcapillary venules. A P-selectin-mediated event. J. Immunol. 152, 3570-3577 (1994).

30. Nussbaum, C. et al. Neutrophil and endothelial adhesive function during human fetal ontogeny. J. Leukoc. Biol. 93, 175-184 (2013).

31. Frommhold, D. et al. RAGE and ICAM-1 cooperate in mediating leukocyte recruitment during acute inflammation in vivo. Blood 116, 841-849 (2010).

32. Murakami, A. et al. Sphingosine 1-phosphate (S1P) regulates vascular contraction via S1P3 receptor: investigation based on a new S1P3 receptor antagonist. Mol. Pharmacol. 77, 704-713 (2010).

33. van Mourik, J. A., Romani de Wit, T. \& Voorberg, J. Biogenesis and exocytosis of Weibel-Palade bodies. Histochem. Cell Biol. 117, 113-122 (2002).

34. An, S., Bleu, T. \& Zheng, Y. Transduction of intracellular calcium signals through $\mathrm{G}$ protein-mediated activation of phospholipase $\mathrm{C}$ by recombinant sphingosine 1-phosphate receptors. Mol. Pharmacol. 55, 787-794 (1999).

35. Sato, K. et al. Activation of phospholipase C-Ca2 + system by sphingosine 1-phosphate in $\mathrm{CHO}$ cells transfected with Edg-3, a putative lipid receptor. FEBS Lett. 443, 25-30 (1999).

36. Chun, J., Hla, T., Lynch, K. R., Spiegel, S. \& Moolenaar, W. H. International Union of Basic and Clinical Pharmacology. LXXVIII. Lysophospholipid receptor nomenclature. Pharmacol. Rev. 62, 579-587 (2010).

37. Korhonen, H. et al. Anaphylactic shock depends on endothelial Gq/G11. J. Exp Med. 206, 411-420 (2009).

38. Schwab, S. R. et al. Lymphocyte sequestration through S1P lyase inhibition and disruption of S1P gradients. Science 309, 1735-1739 (2005).

39. Sensken, S. C. et al. Selective activation of $\mathrm{G}$ alpha i mediated signalling of SIP(3) by FTY720-phosphate. Cell. Signal. 20, 1125-1133 (2008).

40. French, K. J. et al. Discovery and evaluation of inhibitors of human sphingosine kinase. Cancer Res. 63, 5962-5969 (2003).

41. Cleator, J. H., Zhu, W. Q., Vaughan, D. E. \& Hamm, H. E. Differential regulation of endothelial exocytosis of P-selectin and von Willebrand factor by protease-activated receptors and cAMP. Blood 107, 2736-2744 (2006).

42. Rius, R. A., Edsall, L. C. \& Spiegel, S. Activation of sphingosine kinase in pheochromocytoma PC12 neuronal cells in response to trophic factors. FEBS Lett. 417, 173-176 (1997).

43. Prieschl, E. E., Csonga, R., Novotny, V., Kikuchi, G. E. \& Baumruker, T. The balance between sphingosine and sphingosine-1-phosphate is decisive for mast cell activation after Fc epsilon receptor I triggering. J. Exp. Med. 190, 1-8 (1999). 
44. Jolly, P. S. et al. Transactivation of sphingosine-1-phosphate receptors by FcepsilonRI triggering is required for normal mast cell degranulation and chemotaxis. J. Exp. Med. 199, 959-970 (2004).

45. Olivera, A. \& Rivera, J. An emerging role for the lipid mediator sphingosine-1phosphate in mast cell effector function and allergic disease. Adv. Exp. Med. Biol. 716, 123-142 (2011).

46. Stokes, A. J., Shimoda, L. M., Koblan-Huberson, M., Adra, C. N. \& Turner, H. A TRPV2-PKA signaling module for transduction of physical stimuli in mast cells. J. Exp. Med. 200, 137-147 (2004).

47. Zhang, D. et al. Mast-cell degranulation induced by physical stimuli involves the activation of transient-receptor-potential channel TRPV2. Physiol. Res. 61, 113-124 (2011).

48. Pan, S. et al. A monoselective sphingosine-1-phosphate receptor-1 agonist prevents allograft rejection in a stringent rat heart transplantation model. Chem. Biol. 13, 1227-1234 (2006).

49. Matsushita, K., Morrell, C. N. \& Lowenstein, C. J. Sphingosine 1-phosphate activates Weibel-Palade body exocytosis. Proc. Natl Acad. Sci. USA 101, 11483-11487 (2004)

50. Florey, O. \& Haskard, D. O. Sphingosine 1-phosphate enhances Fc gamma receptor-mediated neutrophil activation and recruitment under flow conditions. J. Immunol. 183, 2330-2336 (2009).

51. Allende, M. L. et al. Sphingosine-1-phosphate lyase deficiency produces a proinflammatory response while impairing neutrophil trafficking. J. Biol. Chem. 286, 7348-7358 (2010).

52. Zhao, Y. et al. Protection of LPS-induced murine acute lung injury by sphingosine-1-phosphate lyase suppression. Am. J. Respir. Cell Mol. Biol. 45, 426-435 (2010).

53. Peng, X. et al. Protective effects of sphingosine 1-phosphate in murine endotoxin-induced inflammatory lung injury. Am. J. Respir. Cell Mol. Biol. 169, 1245-1251 (2004).

54. Sawicka, E. et al. Inhibition of Th1- and Th2-mediated airway inflammation by the sphingosine 1-phosphate receptor agonist FTY720. J. Immunol. 171, 6206-6214 (2003)

55. Salomone, S. \& Waeber, C. Selectivity and specificity of sphingosine-1phosphate receptor ligands: caveats and critical thinking in characterizing receptor-mediated effects. Front. Pharmacol. 2, 9 (2011).

56. Nofer, J. R. et al. HDL induces NO-dependent vasorelaxation via the lysophospholipid receptor S1P(3). J. Clin. Invest. 113, 569-581 (2004).

57. Theilmeier, G. et al. High-density lipoproteins and their constituent, sphingosine-1-phosphate, directly protect the heart against ischemia/ reperfusion injury in vivo via the $\mathrm{S} 1 \mathrm{P}(3)$ lysophospholipid receptor. Circulation 114, 1403-1409 (2006).

58. Frenette, P. S. et al. Platelet-endothelial interactions in inflamed mesenteric venules. Blood 91, 1318-1324 (1998).

59. Carvalho-Tavares, J. et al. A role for platelets and endothelial selectins in tumor necrosis factor-alpha-induced leukocyte recruitment in the brain microvasculature. Circ. Res. 87, 1141-1148 (2000).

60. Uemura, T. et al. Biological properties of a specific Galpha q/11 inhibitor, YM-254890, on platelet functions and thrombus formation under high-shear stress. Br. J. Pharmacol. 148, 61-69 (2006).

61. Niessen, F. et al. Dendritic cell PAR1-S1P3 signalling couples coagulation and inflammation. Nature 452, 654-658 (2008).

62. Rosen, H., Gonzalez-Cabrera, P. J., Sanna, M. G. \& Brown, S. Sphingosine 1-phosphate receptor signaling. Annu. Rev. Biochem. 78, 743-768 (2009).

63. Cyster, J. G. \& Schwab, S. R. Sphingosine-1-phosphate and lymphocyte egress from lymphoid organs. Annu. Rev. Biochem. 30, 69-94 (2011).

64. Imeri, F. et al. Novel oxazolo-oxazole derivatives of FTY720 reduce endothelial cell permeability, immune cell chemotaxis and symptoms of experimental autoimmune encephalomyelitis in mice. Neuropharmacology 85, 314-327 (2014).

65. Gossens, K. et al. Thymic progenitor homing and lymphocyte homeostasis are linked via S1P-controlled expression of thymic P-selectin/CCL25. J. Exp. Med. 206, 761-778 (2009).

66. Choi, J. W. et al. FTY720 (fingolimod) efficacy in an animal model of multiple sclerosis requires astrocyte sphingosine 1-phosphate receptor 1 (S1P1) modulation. Proc. Natl Acad. Sci. USA 108, 751-756 (2010).

67. Gothert, J. R. et al. Genetically tagging endothelial cells in vivo: bone marrowderived cells do not contribute to tumor endothelium. Blood 104, 1769-1777 (2004).

68. Jensen, B. M., Swindle, E. J., Iwaki, S. \& Gilfillan, A. M. Generation, isolation, and maintenance of rodent mast cells and mast cell lines. Curr. Protoc. Immunol. Chapter 3, Unit 323 (2006).

69. Drew, E., Merkens, H., Chelliah, S., Doyonnas, R. \& McNagny, K. M. CD34 is a specific marker of mature murine mast cells. Exp. Hematol. 30, 1211-1218 (2002).

70. Sattler, K. J. E. et al. Sphingosine 1-phosphate levels in plasma and HDL are altered in coronary artery disease. Basic Res. Cardiol. 105, 821-832 (2010).

\section{Acknowledgements}

We thank Susanne Bierschenk for her invaluable help in performing flow chamber experiments. We thank Klaus Seuwen (Novartis) for the kind provision of AUY 954 We are grateful to Franziska Röstel and Mareike Lipinski for lipid extractions and Christina-Maria Reimann for performing lipid analyses. This work was supported by the Deutsche Forschungsgemeinschaft to B.L. (LE940/4-2), M.S. (SP621/4-1), M.H.G. (GR 1943/2-2), B.L., G.H., V.P.P. (SFB656 project A6) and M.S. (SFB914 project B1). M.S. received support from the Deutsches Zentrum für Herz- und Kreislaufforschung. C.F.G.-d.-A., I.R., H.C.d.C.F.N. and M.S. have received funding from the European Community's Seventh Framework Programme [FP7-2007-2013] under grant agreement no. HEALTH-F4-2011-282095.

\section{Author contributions}

C.N., S.B., C.F.G.-d.-A., P.K., V.P.P., I.R., G.H., K.v.W.L. and H.K. performed research, collected data, analysed and interpreted data, performed statistical analysis, wrote the manuscript. M.H.G., H.C.d.C.F.N., J.G., G.H., B.L.-S. and S.O. contributed vital reagents or analytical tools and interpreted data. M.S. and B.L. designed research, analysed and interpreted data, and wrote the manuscript.

\section{Additional information}

Supplementary Information accompanies this paper at http://www.nature.com/ naturecommunications

Competing financial interests: The authors declare no competing financial interests.

Reprints and permission information is available online at http://npg.nature.com/ reprintsandpermissions/

How to cite this article: Nussbaum, C. et al. Sphingosine-1-phosphate receptor 3 promotes leukocyte rolling by mobilizing endothelial P-selectin. Nat. Commun. 6:6416 doi: $10.1038 /$ ncomms7416 (2015)

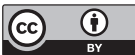

This work is licensed under a Creative Commons Attribution 4.0 International License. The images or other third party material in this article are included in the article's Creative Commons license, unless indicated otherwise in the credit line; if the material is not included under the Creative Commons license, users will need to obtain permission from the license holder to reproduce the material. To view a copy of this license, visit http://creativecommons.org/licenses/by/4.0/ 